\title{
Potential and Challenges of Improving Photosynthesis in Algae
}

\author{
Valeria Vecchi ${ }^{\dagger}$, Simone Barera ${ }^{\dagger}$, Roberto Bassi and Luca Dall’Osto * \\ Dipartimento di Biotecnologie, Università di Verona, Strada Le Grazie 15, 37134 Verona, Italy; \\ valeria.vecchi@univr.it (V.V.); Simone.barera@univr.it (S.B.); roberto.bassi55@gmail.com (R.B.) \\ * Correspondence: luca.dallosto@univr.it; Tel.: +39-045-8027806; Fax: +39-045-8027929 \\ + These authors contributed equally to this work.
}

Received: 28 November 2019; Accepted: 30 December 2019; Published: 3 January 2020

check for updates

\begin{abstract}
Sunlight energy largely exceeds the energy required by anthropic activities, and therefore its exploitation represents a major target in the field of renewable energies. The interest in the mass cultivation of green microalgae has grown in the last decades, as algal biomass could be employed to cover a significant portion of global energy demand. Advantages of microalgal vs. plant biomass production include higher light-use efficiency, efficient carbon capture and the valorization of marginal lands and wastewaters. Realization of this potential requires a decrease of the current production costs, which can be obtained by increasing the productivity of the most common industrial strains, by the identification of factors limiting biomass yield, and by removing bottlenecks, namely through domestication strategies aimed to fill the gap between the theoretical and real productivity of algal cultures. In particular, the light-to-biomass conversion efficiency represents one of the major constraints for achieving a significant improvement of algal cell lines. This review outlines the molecular events of photosynthesis, which regulate the conversion of light into biomass, and discusses how these can be targeted to enhance productivity through mutagenesis, strain selection or genetic engineering. This review highlights the most recent results in the manipulation of the fundamental mechanisms of algal photosynthesis, which revealed that a significant yield enhancement is feasible. Moreover, metabolic engineering of microalgae, focused upon the development of renewable fuel biorefineries, has also drawn attention and resulted in efforts for enhancing productivity of oil or isoprenoids.
\end{abstract}

Keywords: photosynthesis; microalgae; biomass productivity; NPQ; light-harvesting; complex PSII; RuBisCO; renewable energies; strain domestication

\section{Introduction}

\subsection{Why Study Photosynthesis in Microalgae?}

Oxygenic photosynthesis is the process by which photoautotrophs capture sunlight efficiently and converts it into organic molecules and biomass with an efficiency which is, instead, variable, depending on species and environmental conditions [1]. Oxygenic photosynthetic organisms, namely plants, algae and cyanobacteria, store into biomass the solar energy that reaches the Earth's surface at a rate of 120,000 terawatt/year (TW-y) [2]. The current global energy demand of $14.9 \mathrm{TW}-\mathrm{y}$, although it is projected to increase to $23.4 \mathrm{TW}-\mathrm{y}$ by 2030, yet falls greater than three orders of magnitude behind the solar energy on Earth. Therefore, exploitation of this potential by culturing photoautotrophs could satisfy at least part of the energy required for anthropic activities.

Among photosynthetic organisms, cyanobacteria and eukaryotic microalgae are the most promising feedstocks for the sustainable production of bulk bio-based materials such as food, feed, fuel 
and high-value metabolites; moreover, they can be used for wastewater treatments and in mitigation processes for $\mathrm{CO}_{2}$-emissions [3]. Algae can grow autotrophically, heterotrophically or mixotrophically in massive cultures for industrial purposes, in either open ponds or closed photobioreactors (PBRs). In contrast with land plants, algae do not require arable land and need far less fresh water for their growth. Moreover, the culture biomass devoid of stems and roots, which consumes metabolic energy, is fully photosynthetically active. Finally, biomass productivity is far less affected by the seasonal cycle [3]. However, while microalgae represent a promising source of valuable bio-based products, an optimization of cultivation technologies is required in order to enhance growth rates and cell densities at saturation, thus making the process profitable [4]. Indeed, productivity in photobioreactors is reduced by the inefficient light-to-biomass conversion, that leads to a photosynthetic efficiency significantly lower than the theoretical maximum of $9-10 \%$, corresponding to $\sim 80 \mathrm{~g}$ of biomass $/ \mathrm{m}^{2} /$ day or 280 ton/ha/year [5]. In the industrial scale PBRs, algae light conversion yield falls between 3\% and 5\% [5]. Filling the gap that originates from light-use inefficiency, and that makes the controlled cultivation of microalgae still far from being commercially viable, is therefore essential. Comprehension of the mechanism regulating photosynthesis will allow researchers to identify the targets for genetic improvement and ultimately to enhance biomass yield, thus counterbalancing the costs for cultivation systems and downstream biomass processing.

\subsection{Microalgal Species of Interest for Research on the Regulatory Mechanisms of Photosynthesis}

Eukaryotic microalgae are classified according to their pigment content into Rhodophyta (red algae), Chrysophyceae (golden algae), Phaeophyceae (brown algae) and Chlorophyta (green algae) [6]. Chlorophyta includes most genera currently employed for biotechnological applications [3]. The best studied green microalgal species is certainly the model organism Chlamydomonas reinhardtii. The major reasons for this preeminent position in photosynthesis research resides in its haploid genetic organization, allowing the mutant phenotypes to be detected at the first generation without the need for segregation; moreover, sexual reproduction can be induced by modulating the growth conditions, it can be transformed in all its genomes (nuclear, chloroplastic and mitochondrial), and it is mixotrophic, thus allowing for the isolation of mutants with impaired photosynthesis [7]. Finally, a short life cycle makes it a good platform to study light-to-biomass conversion efficiency and to optimize photosynthesis [8]. Besides Chlamydomonas, genetic tools have been developed for other species of green algae, which have an exploitation potential for high-value chemicals production [3]. Among those, Chlorella zofigiensis accumulates high-value carotenoids and has high biomass and lipid productivity [9]; several species belonging to the genus Chlorella are of interest for human health supplements [10] and biofuel production [11]. Moreover, domestication strategies have been developed in C. sorokiniana to generate mutant strains with enhanced biomass productivity [12]. In other Chlorophyta, limitations related to the lack of optimized genetic tools still exist, and particularly concern strains relevant for industrial applications: Dunaliella salina, extensively cultured in open ponds and photobioreactor for $\beta$-carotene [13] and lipids production [14] and Haematococcus pluvialis, an industrial source of astaxanthin [15]. Members of the Nannochloropsis genus, and the diatom Phaeodactylum tricornutum, all belonging to Heterokonta, are obligate photoautotrophs that have been intensively characterized, and are also well-developed models for studying microalgal molecular physiology and genetic engineering. The photosynthetic mechanisms of different species such as Nannochloropsis gaditana, N. oceanica or N. oculata have been investigated because of their unique photosynthetic architecture among Heterokonta, characterized by Chl $a$ as the only primary pigment and high content of violaxanthin and vaucheriaxanthin [16]; moreover, light regimes and nutrient starvation induce rapid triacylglycerols (TAGs) biosynthesis in these oleaginous strains, that are therefore considered promising for biodiesel production [17]. Phaeodactylum tricornutum, a species with a fully sequenced genome, is interesting for its high lipid content and for a peculiar light-harvesting system, binding the xanthophyll fucoxanthin (Fx), Chls $a$ and $c[18,19]$. 
In this review we mainly focused on green microalgae and diatoms, citing other species whenever it is considered relevant.

\section{Photosynthesis}

In both green algae and higher plants, the process of oxygenic photosynthesis can be divided into light and dark phases. In the former, photons are absorbed and utilized to drive Linear and Cyclic Electron Transfer (LET and CET, respectively), to form adenosine triphosphate (ATP) and the reduced form of Nicotinamide adenine dinucleotide phosphate (NADPH), which power the Calvin-Benson-Bassham cycle to produce carbohydrates in the dark phase (Figure 1).



Figure 1. Schematic representation of photosynthetic electron transport. Arrangement of Photosystem I (PSI), Photosystem II (PSII), cytochrome b6f and adenosine triphosphate (ATP) synthase complexes within the thylakoid membranes is shown. The light-driven water splitting reaction leads to $\mathrm{O}_{2}$ evolution and originates linear electron transport (LET), indicated with black arrows, from water to nicotinamide adenine dinucleotide phosphate $\left(\mathrm{NADP}^{+}\right)$, which is coupled to proton translocation from stroma into the luminal side of thylakoids during the light phase. The electrochemical gradient formed is used by the ATP synthase to produce ATP from Adenosine diphosphate (ADP) and Pi in the stroma. The NADPH and ATP formed during the light phase drive the Calvin-Benson-Bassham cycle reactions in the stroma. Two pathways of cyclic electron transport (CET) around PSI are indicated with red (Ferredoxin-dependent pathway) and green (NDA2-dependent pathway) arrows, respectively.

\subsection{The Light Phase of Photosynthesis}

The linear electron transport (LET) reaction starts with the water-splitting complex Photosystem II (PSII), that captures sunlight and utilizes excitation energy to oxidize water molecules into protons $\left(\mathrm{H}^{+}\right)$ and molecular oxygen $\left(\mathrm{O}_{2}\right)$. The electrons removed from water are transferred via the Plastoquinone (PQ) pool to the Cytochrome $b_{6} f\left(\mathrm{Cyt} b_{6} f\right)$ complex and then utilized to translocate protons across the thylakoid membrane. The cytochrome $f$ subunit reduces the soluble electron carriers' plastocyanin (PC), the electron donors of PSI. Absorption of photons by Photosystem I (PSI) promotes oxidation of its reaction centre $(\mathrm{RC})$ P700. The electron removed by the oxidation event finally reduces ferredoxin (FDX) and the electron hole in $\mathrm{P} \mathrm{O0}^{+}$is filled by electrons from PC [20], while at the stromal side the ferredoxin $\mathrm{NADP}^{+}$reductase (FNR) transfers the electrons from FDX to $\mathrm{NADP}^{+}$to yield NADPH $+\mathrm{H}^{+}$. This electron transport is coupled to the build-up of a proton gradient across the thylakoid membrane, with contributions from water splitting and $\mathrm{PQH}_{2}$ oxidation by the Cyt $b_{6} f$. The return of protons to the stromal compartment is coupled to ATP synthesis [20]. 
The ATP:NADPH ratio is regulated by modulating LET and CET, the latter being the reaction which reduces PQ with excess reducing equivalent from FDX or NADPH [21] (Figure 1). In C. reinhardtii, two CET pathways around PSI are suggested: The NADPH-dependent pathway involves type II NAD(P)H-dehydrogenase (NDA2), which recycles electrons from PSI into the intersystem chain via NADPH [22]. The secondary FDX dependent pathway is mediated by two proteins: PROTON GRADIENT REGULATION 5 (PGR5) and PGR5-LIKE PHOTOSYNTHETIC PHENOTYPE 1 (PGRL1) [23] (Figure 1).

\subsubsection{Light-Harvesting Systems: PSI-LHCI and PSII-LHCII Supercomplexes Organization in Microalgae}

Capture of light energy by both photosystems, which drives charge separation in RC and fuels LET and CET, is enhanced by pigment-binding proteins, the light-harvesting complexes (LHC). Various LHCs form the peripheral antenna system in both photosystems [24]. While RC subunits were strongly conserved, the antenna complexes diversified through evolution [24,25], yet maintained a common architecture [26,27]. The most represented member is the major antenna LHCII, a $22 \mathrm{kDa}$ polypeptide which binds 14 chlorophylls (Chl) $a$ and $b$, and four xanthophylls (Lutein, Neoxanthin, Violaxanthin and, upon high light exposure, Zeaxanthin) [28] (LHC)-like antenna proteins, which were present in a cyanobacterial ancestor, carried out photoprotective functions [29], while they later evolved into isoforms fulfilling either light-harvesting or energy-dissipative responses. The LHC superfamily consists of some 30 proteins, the most conserved being the subunits of PSI and PSII through the Chlorophyta [30], which have pre-eminently a light-harvesting role, while the light-harvesting complex stress-related (LHCSR) subunits have an energy-dissipative role, enabling photoprotection in excess light (EL) conditions through the non-photochemical quenching (NPQ) mechanism [31] (see Section 2.3). In C. reinhardtii, the LHCI subunits, forming the PSI peripheral antenna system, and the monomeric subunits of the PSII supercomplex Lhcb4 (CP29) and Lhcb5 (CP26), are the most conserved antenna proteins. Trimeric LHCIIs, the major antennae of photosynthetic membranes of $C$. reinhardtii, are encoded by Lhcbm genes (Lhcbm1-9).

\section{PSII-LHCII}

The core complex of PSII is highly conserved in all organisms and consists of 40 different protein subunits. The RC is composed by subunits D1, D2 and cytochrome $b_{559}$ and hosts P680, the PSII RC where the primary charge separation event occurs. Light-dependent transfer of reducing equivalents to $\mathrm{PQ}$ leads to $\mathrm{P} 680^{+}$formation. The positive charges accumulated by four events of charge separation drive the water splitting reaction within the oxygen evolving complex (OEC), composed by the extrinsic polypeptides PsbO, PsbQ, PsbP and PsbR. Chl $a$ - and $\beta$-carotene-binding inner antennae CP43 and CP47 enlarge the light harvesting capacity of the supercomplex. The PSII core is organized into dimers $(\mathrm{C} 2)$, which, in turn coordinate a peripheral antenna system (see above). In higher plants, this LHC system is made of two layers: The inner, composed by the monomeric LHC proteins CP24, CP26 and CP29 [32], which are bound, respectively, to the $\mathrm{CP} 43$ and $\mathrm{CP} 47$ core subunits, and the outer layer is made by the trimeric LHCII complexes [33]. In C. reinhardtii, the largest PSII-LHCII supercomplex characterized contains three LHCII trimers (named S, M and N) per monomeric core, and it is characterized by the absence of the monomeric antennae protein CP24. In mosses and higher plants, the $\mathrm{N}$ trimer has been substituted for by an additional monomeric LHC, CP24 (Lhcb6), LhcbM1, LhcbM2/7 and LhcbM3, which are the major components of LHCII trimers in the PSII supercomplex of C. reinhardtii [34] (Figure 2). Recently, Shen and co-workers reported a cryo-electron microscopy structure of a complete, $\mathrm{C}_{2} \mathrm{~S}_{2} \mathrm{M}_{2} \mathrm{~N}_{2}$-type PSII-LHCII supercomplex from C. reinhardtii at 3.37-A resolution. The high-resolution structure allowed not only locating the LHCII trimers in the complex, but also the plausible energy transfer pathways from the peripheral antennae to the PSII core. Moreover, a number of small core subunits (PsbE, PsbF, PsbH, PsbI, PsbJ, PsbK PsbL, PsbM, PsbTc, PsbW, PsbX and PsbZ) has been elucidated [35]. 


\section{Chlamydomonas reinhardtii}



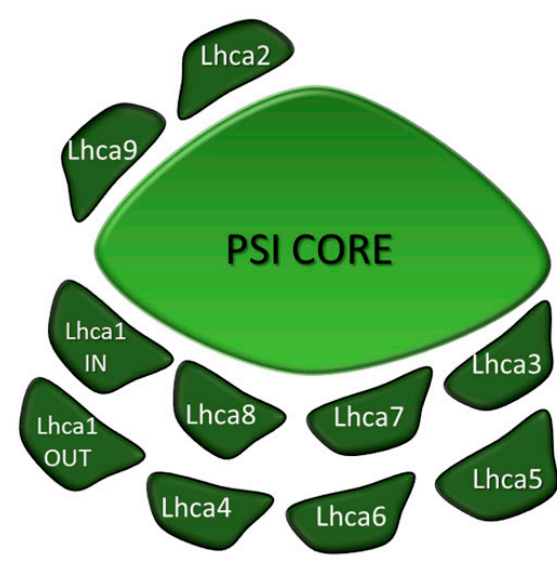

PSI-LHCI

complex

Figure 2. Supramolecular organization of PSII-LHCII and PSI-LHCI supercomplexes in the model alga Chlamydomonas reinhardtii. The schematic representations are based upon data from [33] for PSII-LHCII and from [36] for PSI-LHCI. The core complexes of both PSs are shown in light green while the antenna complexes are shown in dark green.

\section{PSI-LHCI}

The organization of PSI-LHCI of C. reinhardtii was investigated by negative stain electron microscopy and single particle analysis, which revealed that the supercomplex is larger but less stable than that from higher plants. The Lhca1-9 antenna proteins loosely bind to the core, where this can explain the large variation in antenna composition of PSI-LHCI from C. reinhardtii found in the literature. The isolation of several PSI-LHCI supercomplexes with different antenna size allowed to precisely determine the position of Lhca2 and Lhca9 proteins and led to a model of whole PSI-LHCI supercomplex antenna organization [36]. Moreover, a megacomplex constituted by a Cyt $b_{6} f$ interacting with the PSI-LHCI complex was identified under anaerobic conditions, a treatment that promotes CET in C. reinhardtii [37]. More recently, the structure of C. reinhardtii PSI-LHCI supercomplex has been solved by cryo-electron microscopy, showing that up to ten LHCIs are associated with the PSI core [38] (Figure 2).

\subsection{The Dark Phase of Photosynthesis}

In green algae and higher plants, the carbon dioxide reduction occurs in the dark phase of photosynthesis, which also occurs in the light, and is powered by the NADPH and ATP from the light phase. The whole process can be described with the general reaction:

$$
\begin{aligned}
& \begin{array}{l}
\text { 2NADPH }+\mathrm{H}+3 A T P \\
\text { Enzymes }
\end{array}\left(\mathrm{CH}_{2} \mathrm{O}\right)+\mathrm{H}_{2} \mathrm{O}
\end{aligned}
$$

The entire process of carbon fixation, discovered by Calvin, Benson and Bassham in the early 1950s, requires two molecules of NADPH and three of ATP for each $\mathrm{CO}_{2}$ fixed into sugars. This energy complement is supplied by the absorption of eight photons in the light phase. 


\subsubsection{Dark Reactions of Photosynthesis: The Calvin-Benson-Bassham Cycle}

The conversion of $\mathrm{CO}_{2}$ into sugar (or other compounds) is performed by three distinct phases (carboxylation, reduction and regeneration phases) within the Calvin-Benson-Bassham cycle (CBBc) (Figure 3). During the carboxylation phase, one molecule of $\mathrm{CO}_{2}$ is added to the 5-carbon sugar ribulose bisphosphate $(\mathrm{RuBP})$ by the enzyme ribulose bisphosphate carboxylase/oxygenase (RuBisCO) to form two molecules of phosphoglycerate (3-PGA). The enzyme is controlled by the RuBisCO-activase, which carboxylates a Lys residue in the presence of the substrate $\mathrm{CO}_{2}$, thus preventing wasteful reaction with $\mathrm{O}_{2}$ under $\mathrm{CO}_{2}$-depleted conditions. The subsequent reduction phase catalyses the conversion of 3-PGA into 3-carbon (Triose-P) products glycerhaldeide-3-P (G3P) in two steps, by consuming ATP and NADPH. The regeneration phase restores the initial RuBP reactant from Triose-P, through a complex series of reactions which involves eight distinct enzymes (Figure 3), including transketolase and transaldolase, yielding 5-carbon sugars from 6-carbon plus 3-carbon sugar intermediates, and the sedoheptulose-1,7-bisphosphatase that catalyses the de-phosphorylation of sedoheptulose-1,7-bisphosphate to yield sedoheptulose-7-phosphate. sedoheptulose-1,7-bisphosphatase activity shows a strong correlation with the rate of photosynthetic carbon fixation, thus controlling carbon flux [39]. Under EL conditions, the RuBisCO activity rate becomes limiting, and the rate of synthesis of ATP/NADPH from light reactions exceeds their use by CBBc. Depletion of ADP limits ATPase activity in protons' return to the stroma compartment, leading to lumen iper-acidification and triggering excess energy dissipation reactions. This is further enhanced by NADPH accumulation, since CET activation further acidifies the lumen.

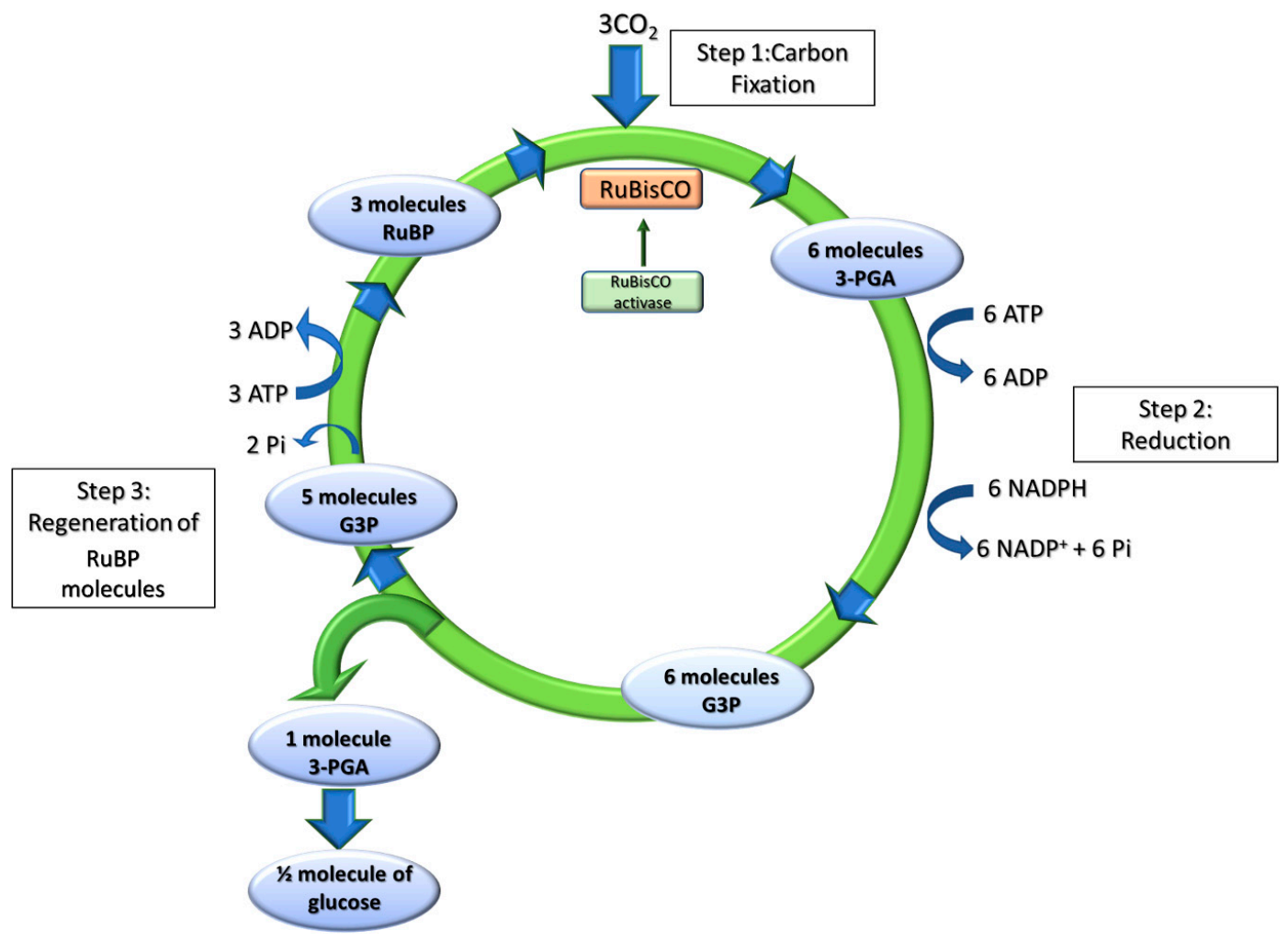

Figure 3. The Calvin-Benson-Bassham cycle (CBBc) reactions. The CBBc has three stages. In stage 1, the enzyme RuBisCO incorporates $3 \mathrm{CO}_{2}$ molecules into the 5-carbon sugar ribulose-1,5-bisphosphate (RuBP) to form 6 molecules of 3-phosphoglycerate (3-PGA). In stage 2, 6 molecules of 3-PGA are converted into 6 molecules of Glyceraldehyde-3-P (G3P) by using 6 molecules of ATP and 6 molecules of NADPH as reducing power. In stage $3, \mathrm{RuBP}$ is regenerated so that the cycle can continue. Stage 3 includes a complex series of reactions combining 3-, 4-, 5-, 6-, and 7-carbon sugar phosphates, which are not explicitly shown in the diagram. 


\subsection{2. $\mathrm{RuBisCO}$}

In cyanobacteria and plants, along with red, brown and green algae, $\mathrm{RuBisCO}$ is found as a large protein complex with a hexadecameric quaternary structures consisting of eight 55-kDa large (L) subunits and eight $15-\mathrm{kDa}$ small $(\mathrm{S})$ subunits $\left(\mathrm{L}_{8} \mathrm{~S}_{8}\right)$. The RuBisCO crystal structure was determined on complexes purified from Spinacia oleracea, Nicotiana tabacum [40] and the cyanobacterium Synechococcus [41]. In green algae the crystal structure of $C$. reinahardtii at 1.4 A resolution [42] showed high similarity to the $\mathrm{L}_{8} \mathrm{~S}_{8}$-RuBisCO enzyme assembly from Spinacia oleracea. Since RuBisCO evolved in atmosphere with a higher concentration of $\mathrm{CO}_{2}$ respect to the current one, it has low affinity for $\mathrm{CO}_{2}$ and low substrate specificity. Thus, it accepts oxygen as substrate at low $\mathrm{CO}_{2}$, which leads to the loss of fixed carbon as a consequence of feeding a photorespiratory cycle with phosphoglycolate. Although the photorespiratory (C2) cycle recovers part of phosphoglycolate into phosphoglycerate, this reduces the overall light-to-biomass conversion efficiency. In both green algae and higher plants, the ability to fix $\mathrm{CO}_{2}$ depends in part upon the properties of RuBisCO: While RuBisCO isolated from a few species of red algae have three times higher substrate specificity vs. that from C3 crop species [43], in most of photoautotrophs RuBisCO is operating at no more than $30 \%$ of its capacity under standard atmospheric conditions $\left(21 \% \mathrm{O}_{2}, 0.04 \% \mathrm{CO}_{2}\right)$. Indeed, the chloroplastic abundance of this protein is extremely high. To overcome this drawback, many photosynthetic organisms have developed different systems to increase the level of $\mathrm{CO}_{2}$ at the catalytic site in order to enhance the carboxylation while disfavouring the oxygenation reaction. Microalgae absorb $\mathrm{HCO}_{3}{ }^{-}$ions, which must be converted to $\mathrm{CO}_{2}$ before the carbon fixation takes place. Moreover, in green algae RuBisCO is compartmentalized into carbon-concentration sub-compartments of the chloroplast, called pyrenoids, which have been purified from C. reinhardtii [44] and shown they consist primarily of RuBisCO. In other algae types including red algae, carboxysomes are present as large molecular architectures including carbonic anhydrase together with RuBisCO, where $\mathrm{CO} 2$ level is increased from carbonic anhydrase activity to limit photorespiration and enhance photosynthetic yield [45].

\subsection{Dynamics of the Photosynthetic Apparatus in Response to Environmental Conditions: Photoprotective Mechanisms}

During evolution, photosynthetic organisms are said to have adapted to a wide range of habitats with an extreme variability of light irradiances, water and nutrient abundance and temperature. Abiotic stresses such as drought or nutrient deprivation easily decrease the maximum photosynthetic yield of algae, thus environmental conditions can exacerbate EL stress. In this condition, the energy absorbed exceeds the rate of its utilization by downstream reactions, increases the concentration of Chl-excited singlet states $\left({ }^{1} \mathrm{Chl}{ }^{*}\right)$, thus the probability of $\mathrm{Chl}$ triplet states $\left({ }^{3} \mathrm{Chl}{ }^{*}\right)$ formation together with the release of singlet oxygen $\left({ }^{1} \mathrm{O}_{2}\right)$, a reactive oxygen species (ROS). It comes that a mechanism to dissipate the excitation energy absorbed in excess, is required. Experiencing EL conditions activate the Non-Photochemical Quenching (NPQ) process. This can be experimentally observed as a decrease of fluorescence emitted by PSII upon exposure to over-saturating light. NPQ arises from a number of processes in the thylakoid membranes, and several major components of NPQ can be identified based on the kinetics curves of the relaxation of PSII fluorescence [46]. The fastest component, immediately triggered upon exposure to EL, is the energy-dependent quenching $(\mathrm{qE})$, which relaxes within approx. one minute upon switching actinic light off.

State transitions (STs) represent changes in the relative antenna sizes of photosystems [47], however although this fluorescence decline (called qT) has been included in NPQ, it is caused by PSI RC activity, and therefore is of the photochemical type. An additional quenching component, that rises and relaxes at a longer time scale than $\mathrm{qE}$, is called qZ [48]: This is found in some algae species in which a zeaxanthin-dependent enhancement of NPQ is observed [49]. The slowest component, named qI, develops under long lasting (several hours) high light stress [46].

The $\mathrm{qE}$ response is dependent on a low lumenal $\mathrm{pH}$ and requires LhcsR, Chl-xanthophyll-binding proteins found in eukaryotic algae and mosses [50] and is replaced by the non-pigmented protein PsbS 
in higher plants [51,52]. In C. reinhardtii, LhcsR proteins are encoded by three highly homologous genes LhcsR1, LhcsR3.1 and LhcsR3.2, while PsbS by two closely linked PsbS1 and PsbS2 genes. Both PsbS and LhcsR proteins harbour protonatable residues exposed to the luminal side, which detect low $\mathrm{pH}$ and activate the heat dissipation of energy absorbed in excess [53,54]. In C. reinhardtii, accumulation of gene products involved in $\mathrm{qE}$ is induced by signals such as high light, blue light and UV light via increased expression of genes encoding for LhcsR and PsbS. By a forward genetics approach, SPA1 and CUL4 have been identified as components of a putative green algal E3 ubiquitin ligase complex, as critical factors in a signalling pathway that controls light-regulated expression of the dissipative response. The accumulation of two isoforms of LhcsR protein LhcsR1 and LhcsR3 is different. Recently, it has been found that the expression of LhcsR1 protein is constitutive, while the accumulation of LhcsR3 is increased under EL conditions and depends on the activation of the CAS [55,56] calcium sensor. Upon protonation, C. reinhardtii LhcsR subunits switch to a quenching conformation. The dynamics of LhcsR proteins transition between unquenched and quenched conformations has been studied in the moss protein LhcsR1 [57-59], showing a 50-fold decrease in lifetime from $3.7 \mathrm{~ns}$ lifetime to $80 \mathrm{ps.}$ The physicochemical mechanisms involved were identified to be dual: (i) the transient formation of carotenoid radical cation, thermally recombining to ground state [60-62], and (ii) the energy transfer from a Chl $a$ to lutein S1 state, which thermally relaxes to the ground state within approx. 10 ps [61]. Thus, the two types of quenching mechanism reported for plants, as localized, respectively, in two different types of LHC subunits $[61,63,64]$, appear to be both active within the single LhcsR subunit [57]. Under EL conditions, lumen acidification triggers the so-called xanthophyll cycle, which involves the xanthophylls violaxanthin (Vio) and zeaxanthin (Zea), and consists of a light-dependent, rapid and reversible de-epoxidation of Vio to Zea. The reaction is catalysed by VDE (violaxanthin de-epoxidase). This enzyme is luminal in plants where it is activated by acidification, while it is stromatic in Chlamydomonas [65]; the xanthophyll cycle of intact Chlamydomonas cells is inhibited by the uncoupler nigericin, indicating that the activation of this stromal enzyme also requires the build-up of a $\mathrm{pH}$ gradient in EL. The amplitude of $\mathrm{qE}$ in plants correlates with the level of Zea though its binding to specific LHC targets, in C. reinhardtii NPQ amplitude is Zea-independent [66]. The qT component of NPQ is dependent on ST, i.e., the mechanism of LHCII relocation between PSs, which compensates for PSI/PSII excitation imbalance and optimizes photosynthetic electron transport in response to the light conditions. PSII over-excitation reduces $\mathrm{PQ}$ to $\mathrm{PQH}_{2}$, and activates a thylakoid protein kinase (STT7 in green algae and STN7 in higher plants) which, in turn, phosphorylates LHCII, and leads to its reversible association with the PSI-LHCI complex [67]. In C. reinhardtii, most of LhcbM proteins get phosphorylated upon ST, including the monomeric antennae CP29 and CP26, which are recruited as a supplementary antenna for PSI. While this mechanism is widespread in green photosynthetic organisms, in plants the amplitude of ST is lower than in C. reinhardtii, possibly indicating differences in the regulation of photosynthetic electron transport. The term "qI" refers to all quenching processes relaxing slowly (>10 $\mathrm{min}$ ), and comprises multiple processes contributing to the down-regulation, inactivation and damaging of PSII. One of the components of the slowly-relaxing NPQ correlates with the synthesis of Zea, was shown as $\Delta \mathrm{pH}$-independent, and is possibly related to the binding of Zea to specific antenna proteins [68]. A second component of NPQ is related to photoinhibition and is enhanced upon prolonged over-excitation. It consists into a light-induced reduction of the quantum yield of PSII, due to the photodamage of the RC protein D1. Thus, quenching relaxation reflects the kinetic of RC repair cycle [20].

The NPQ mechanism is highly relevant for the maintenance of the photosynthetic efficiency which contributes to acclimation to the different light environments. The relative contribution of each of the NPQ components changes between organisms and irradiances: $\mathrm{qE}$ activates based on sudden increases in light intensity, while ST responds to changes in the light spectrum under low light conditions. Thus, LhcsR protein function is synergically with other photoprotective mechanisms, such as CET and ST in shaping the fast response to environmental conditions. Long-term stresses occur on timescales of days and weeks. Photoacclimation mechanisms to such changes involve a 
rearrangement at the level of chloroplast protein and lipid composition yielding into an adjustment of the stoichiometry of photosynthetic complexes through the modulation of gene expression and synthesis/degradation of individual chloroplast components. A major component of response to excess light consists into down-modulating the size of the PSII antenna [69], and enhancing the stoichiometry of the $\mathrm{Cyt} b_{6} f$ complex, ATPase and RuBisCO with respect to PSII RC. In green algae, EL down-regulates LHCII and LHCI genes transcription, while when under limiting irradiance, the opposite response was shown $[70,71]$. In $C$. reinhardtii the increase in the $C h l a / b$ ratio is consistent with decreases in the amount of both LHCI and LHCII in EL [70,72,73]; EL stress also induces an accumulation of proteins involved in the NPQ response, such as LhcsR3 in C. reinhardtii [72,74]. Moreover, the LhcbM isoforms are expressed differentially depending on growth conditions, which suggests a specific role of different LHC complexes in PSII organization and chloroplast photoprotection [75-77]. LhcbM9 is only expressed in stressing conditions and binds to PSII-LHCII complexes, where it protects PSII by inducing an energy-dissipative state with reduced ${ }^{1} \mathrm{O}_{2}$ formation [77]. In C. reinhardtii, the transcriptional regulation of $L h c b M$ genes is mediated by nucleic acid binding 1 protein (NAB1), a cytosolic protein that prevents the translation of LhcbM by sequestering the corresponding mRNAs into translationally silent ribonucleoprotein complexes [78] (Figure 4). The relative abundance of NAB1 is regulated by nutrient abundance: Under $\mathrm{CO}_{2}$ starvation, which hampers the activity of the $\mathrm{CBBc}$, up-regulation of NAB1 promotes an antenna size reduction, thus alleviating the excitation pressure on PSs.
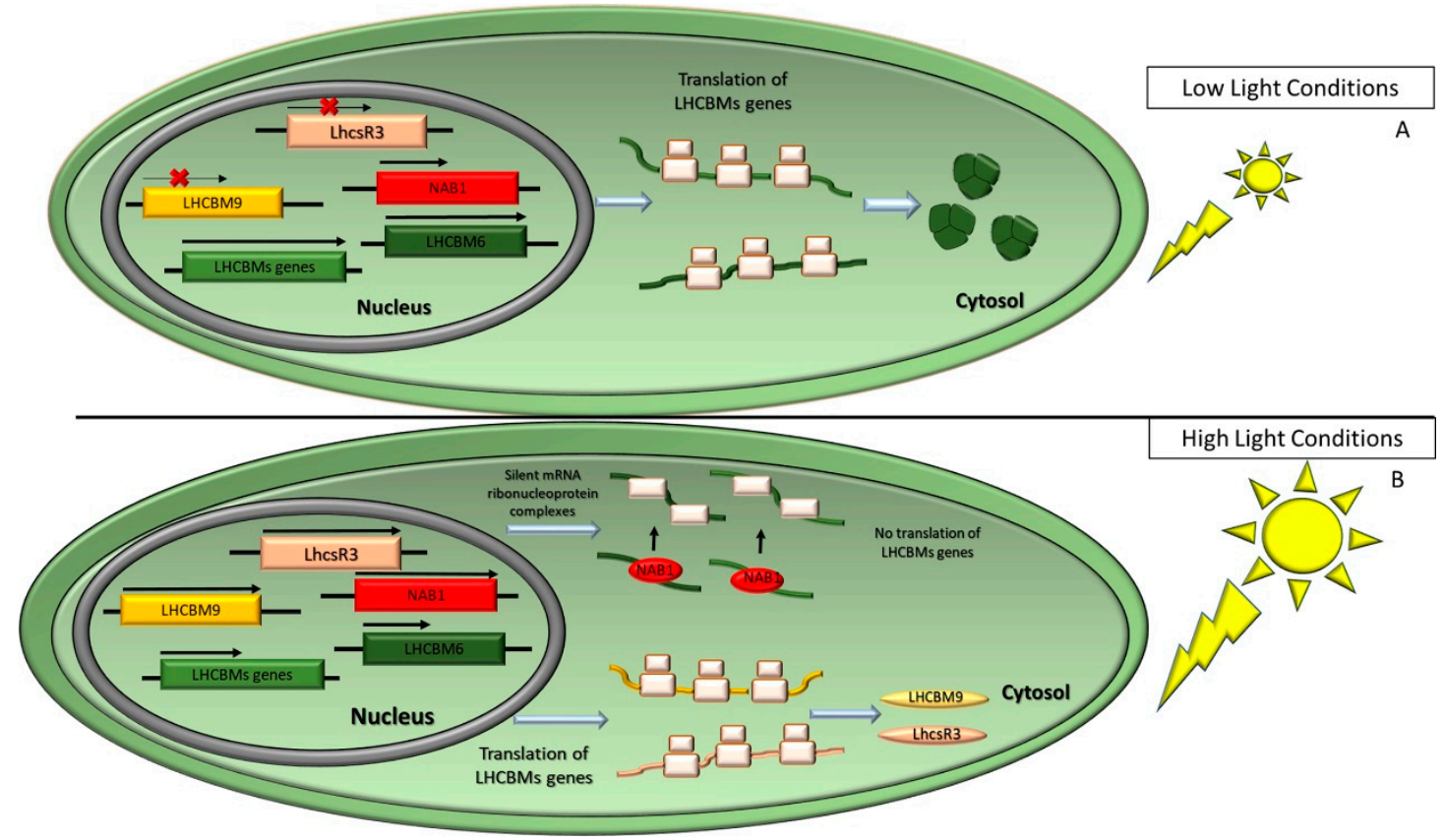

Figure 4. Scheme of long-term control mechanisms regulating light harvesting antenna size, as described in the model alga C. reinhardtii. (A) In low light conditions, carriers of the photosynthetic electron transport chain are oxidized, and all nuclear genes encoding LhcbMs isoforms associated to the PSII are expressed, except for the isoform 9. LhcbM-encoding mRNAs are translated in the cytosol, then targeted to the chloroplast and inserted in the thylakoid membranes. Under low light conditions, the translational repressor NAB1 is in a less active state. (B) In excess light conditions, ATP and NADPH produced by the light reactions exceed their consumption rate by the $\mathrm{CBBC}$, and the overexcitation of PSII results in the release of reactive oxygen species (ROS). To alleviate excitation pressure, a remodelling of the antenna system is induced by slowing down the transcription of LhcbM genes. Once the translation of NAB1 is promoted, this subunit interacts with LhcbM-encoding mRNAs to form silent mRNA-ribonucleoprotein complexes. In contrast to all other isoforms, the expression of LhcbM9 and LhcsR3 proteins are induced. 


\section{Improving Photosynthetic Yield}

\subsection{Light Harvesting Antenna as Target to Reduce Optical Density in Mass Culture}

When grown under mass culture, a condition typical of industrial PBRs, microalgae undergoes a progressive drop in productivity as the cell density gradually increases. This can be mainly ascribed to an inhomogeneous light distribution within the culture, due to its high optical density: In this condition, the surface layers of the culture easily reach the saturation of photosynthesis (and possibly photoinhibition), while the inner layers are light-limited. Such steep gradient in light penetration results in a low productivity of the system. Optimization of the light transmittance within the culture volume was proposed as a strategy to alleviate these constraints. A bioengineering approach to decrease the $\mathrm{Chl}$ content per cell, thus minimizing the light absorption and enabling a larger fraction of cell suspension to contribute to overall productivity, was first developed in the model alga C. reinhardtii. Truncated light-harvesting antenna (tla) mutants were obtained by random DNA insertional mutagenesis and selection by $\mathrm{Chl}$ fluorescence imaging. Mutant tla1 showed a significant reduction of $\mathrm{Chl}$ content per cell and a lower functional antenna size of both PSI $(-50 \%)$ and PSII (-65\%) vs. wild type (WT) [79]. In batch culture, tla1 cells yielded a higher $P_{\max }$ at saturating irradiances and higher light-to-biomass conversion efficiency with respect to the WT strain [79]. Gene TLA1 was found to participate in the mechanism of $\mathrm{Chl}$ antenna size regulation, and indeed its over-expression resulted in a larger antenna size for both photosystems and lower $\mathrm{Chl} a / b$ ratio with respect to WT, while its down-regulation by RNAi resulted in the opposite phenotype [80]. Strain tla2 was mutated in the gene encoding the chloroplast-localized signal recognition particle (CpSRP) receptor CpFTSY, whose deletion was responsible for a pale-green phenotype and a lower $\mathrm{Chl} a / b$ ratio than WT [81]. Components of the CpSRP complex, involved in the proper folding of LHCs and targeting of these proteins to the thylakoids, are therefore promising molecular targets to achieve a substantial reduction in $\mathrm{Chl}$ antenna size without impairing the photosynthetic electron transport (Figure 5) [82]. Moreover, CRISPR-Cas9 technology was recently shown as a reliable approach by which to produce tla mutants [83,84]. Pale-green mutants were obtained in species other than C. reinhardtii (Figure 5): N. gaditana and C. sorokiniana mutant strains with truncated antenna were isolated by random mutagenesis and phenotypic selection; once characterized, they showed higher photosynthetic efficiency than WT and improved photoresistance under EL conditions, in both lab-scale and industrial-scale PBRs [12,85]. An additional molecular target expected to affect antenna size was $C A O$ (encoding for Chlorophyllide $a$ oxygenase) (Figure 5), encoding for the enzyme responsible for $\mathrm{Chl} a \rightarrow \mathrm{Chl} b$ conversion [86]. In Chlamydomonas, both insertional knock-out and point mutations on $C A O$ impaired the biogenesis of antenna systems, which were affected in different ways depending on the light conditions [87]. Moreover, CAO expression was modulated by RNAi, which resulted in knock-down mutants showing a lower $\mathrm{Chl} b$ content. Therefore, by tuning the $\mathrm{Chl} b$ relative abundance, corresponding regulation of antennae size can be obtained, and a reduced optical cross-section improves the growth and photosynthetic rate under high light conditions, without impairing other regulatory mechanisms such as ST and NPQ [88].

Additional perspectives towards enhancing the light use efficiency in algae are likely to be developed in the future based on the emerging functional diversity of individual Lhcm proteins which have been reported to be involved in state1-state2 transitions, NPQ and/or in sustained photoprotection $[75,77]$ thus opening the perspective of enhancing such functions selectively in industrial strains. Nevertheless, it is not yet clear how engineering antennas can be combined with the well-established enhanced growth efficiency of truncated antenna strains $[12,89]$. 




Figure 5. Genes successfully targeted in C. reinhardtii or other species to improve photosynthetic productivity. Improvement of $\mathrm{CO}_{2}$ fixation targets: RuBisCO, RuBisCO activase, $\mathrm{LCI}$ (Low- $\mathrm{CO}_{2}$ Inducible protein), SBPase (sedoheptulose1,7-biphosphatase), FBPase (fructose-bisphosphate aldolase). Optical density reduction: cpSRP pathway (chloroplast signal recognition particle), TLA1 (Truncated Light-Harvesting Antenna 1), LhcbM, NAB1 (nucleic acid binding 1 protein) and CAO (Chlorophyllide $a$ Oxygenase). Green arrows indicate the over-expressed genes, yellow arrows the down-regulated genes and red crosses indicate the knocked-down genes.

\subsection{Bioengineering Response to Light Fluctuations and Improving Resistance to Photo-Inhibition}

The capacity to counteract EL stress and avoid photoinhibition clearly provide a carbon-gain advantage and therefore represent an important component of productivity. In particular, responses to fluctuating light conditions are clearly beneficial for photosynthesis since they enhance the 'tracking' of light, thus maintaining high rates of $C$ assimilation, as shown in field crops [90]. In microalgae, the WT strains show impaired growth when excess irradiance induces photoinhibition, since the repair of photodamage requires metabolic energy. Engineering of the response to EL succeeded in mitigating this loss in efficiency: Very high light resistant (VHL-R) Chlamydomonas strains were selected for their ability to grow at irradiances lethal to the control genotype, and found they were affected in the pathways which regulate photoprotective responses, including PSII repair and ROS detoxification [91]. The Chlamydomonas WT strain was UV-mutagenized and selected on a lethal concentration of Red Bengal, a photoreactive chemical releasing ${ }^{1} \mathrm{O}_{2}$; characterization of tolerant strains identified SOR1 as a factor enhancing resistance to photoinhibition [92]. Analogously, UV-mutagenesis and selection under high irradiance ( $2000 \mu \mathrm{mol}$ photons $\left.\mathrm{m}^{-2} \mathrm{~s}^{-1}\right)$ identified the Light Responsive Signal 1 (LSR1) gene, which conferred improved resistance against exogenous ROS [93]. Recently, Dall'Osto and colleagues [89] applied two steps of mutagenesis and phenotypic selection to Chlorella vulgaris. First, they selected a strain characterized by a $50 \%$ reduction of Chl content per cell and a $30 \%$ increased photon-to-biomass conversion efficiency with respect to WT. After a second mutagenesis cycle followed by a selection on Rose Bengal, they selected pale-green genotypes exhibiting higher resistance to singlet oxygen (strains SOR) that showed a further enhancement in biomass productivity with respect to both parental and WT strains [89].

Alternatively to genetic engineering and mutation/phenotypic selection, an alternative approach consists into sampling and evaluating algal biodiversity, particularly in extreme environments which might provide interesting performance when such strains are grown in optimal conditions. An example of this is the case of Chlorella ohadii, a chlorella strain from the Sinai desert, which was reported to exhibit high productivity and the robustness of growth [94,95]. 


\subsection{RuBisCO as Target to Improve Carbon Assimilation Efficiency}

The rate-limiting step of the $\mathrm{CBBc}$ is the fixation of inorganic carbon catalysed by $\mathrm{RuBisCO}$, as the complex has low turnover rate and low substrate specificity. Moreover, it shows affinity for $\mathrm{O}_{2}$ which leads to futile reactions. The consequences of the wasteful oxygenation reaction are partially alleviated by the photorespiration process which, nevertheless, yields into a partial loss of the $\mathrm{CO} 2$, and thus decreases light-to-biomass conversion efficiency [96]. Therefore, the engineering of microalgal strains with enhanced RuBisCO catalytic activity would be crucial for improving the efficiency of solar energy conversion. Some species of red algae express isoforms with high specific activity [43]. Thus, combining positive mutations from different isoforms has been suggested as a way to obtain RuBisCO with the improved $V_{\max }$ of carboxylation catalysis [97]. A major constraint to this approach is the high intolerance of the catalytic region to mutations, that made sparsely successful direct evolution strategies [96]; nevertheless, some enzymes variants with higher activity have been identified, and their heterologous expression represents a promising approach [98]. Other RuBisCO-improved variants were obtained by site directed mutagenesis, targeting either the rbcL gene (RuBisCO large subunit) or the subunit that interacts with Rubisco activase $[99,100]$. However, their over-expression in Chlamydomonas failed to enhance the $C$ fixation efficiency [101]. On the contrary, the over-expression of endogenous RuBisCO activase in Nannochloropsis oceanica increased biomass and lipid productivity up to 40\% (Figure 5) [102]. Consistently, over-expression of RuBisCO in the cyanobacterium Synechocystis enhanced photosynthetic efficiency and fatty acid productivity (Figure 5) [103,104]. In Chlamydomonas, a number of strategies were tested to improve carbon assimilation. RuBisCO isoforms with the higher $\mathrm{V}_{\max }$ of carboxylation catalysis were obtained by the PCR-based gene shuffling of the rbcL gene consisting into a restriction of encoding DNA following low fidelity replication and re-ligating into random assembled sequences with enhanced biochemical variability [105]. The site-directed mutagenesis of rbcL resulted in a low-activity $\mathrm{RuBisCO}$ variant, which instead triggered a ten-fold higher $\mathrm{H}_{2}$ production in Chlamydomonas, possibly by increasing the pool of reducing equivalents available to the hydrogenase [106]. An alternative approach would alter the engineering of cyanobacterial $\mathrm{CO}_{2}$-concentrating mechanisms, as a possible route to enhance the RuBisCO operating efficiency. Before the approach delivers potential benefits, characterization of algal $\mathrm{HCO}_{3}{ }^{-}$transporters and carbonic anhydrases, and identification of factors regulating $\mathrm{RuBis} \mathrm{CO}$ aggregation into the pyrenoids, is required. Recent advances in dissecting the details of pyrenoid biogenesis in Chlamydomonas [107] might guide future redesign of the mechanism, to augment the overall $\mathrm{C}$ fixation rate.

Besides RuBisCO, other $\mathrm{CBBc}$ enzymes and accessory proteins have been targeted, e.g., sedoheptulose 1,7-bisphosphatase from C. reinhardtii has been successfully over-expressed in D. bardawil, resulting in a significant enhancement of photosynthetic efficiency (Figure 5) [108]. Over-expression of the fructose 1,6-bisphosphatase in Synechocystis enhanced the growth rate with respect to the control genotype under EL conditions (Figure 5) [109]. A strong raise in the photosynthetic productivity of Synechocystis was obtained by over-expressing RuBisCO, sedoheptulose1,7-biphosphatase, fructose-bisphosphate aldolase and trans-ketolase [110].

Finally, by the over-expression of Low- $\mathrm{CO}_{2}$ Inducible (LCI) proteins in C. reinhardtii maintained at high $\mathrm{CO}_{2}$ concentration, namely under conditions which repress LCI synthesis, an increase of biomass productivity up to $80 \%$ with respect to the control genotype was reported (Figure 5) [111].

\subsection{Engineering of the Lipid Biosynthesis for Renewable Energies Production}

The triose phosphate produced by photosynthesis supports the main metabolic pathways of the algal cell, therefore the enhancement of photosynthetic yield potentially results in the enhancement of lipids, proteins and other high value compounds synthesis. Genetic manipulation approaches can generate strains with desirable commercial traits, by either expressing new biosynthetic pathways or enhancing the yield of a product of interest already present in a given strain.

The major research targets is the engineering of strains for a significant increase of total lipid accumulation, and/or the optimization of fatty acid chain-length profile, which can be carried out 
by targeting single or multiple genes involved in the lipid biosynthesis or by down-regulating competing pathways [112,113]. Saturated and mono-unsaturated $\mathrm{C}_{14}-\mathrm{C}_{20}$ fatty acids from microalgae are exploited for renewable liquid biofuel production, while the engineering biosynthesis of long chain-polyunsaturated fatty acids (LC-PUFAs), important components of the human diet, might become a viable option in the market of high-value food additives [114]. Metabolic engineering reports for redirecting carbon fluxes toward fatty acid production in microalgae, included the up-regulation of key biosynthetic enzymes: (i) acetyl-CoA carboxylase, catalysing the first step for fatty acid biosynthesis, was successfully over-expressed in the chloroplast of P. tricornutum [115]; (ii) malonyl-CoA ACP transacylase enzyme, which catalyses the formation of malonyl-ACP, was over-expressed in both $N$. oceanica and Schizochytrium spp., resulting in 31\% and 39.6\% total lipid increase with respect to the control genotype, respectively [116,117]; (iii) acyl-ACP thioesterases (TE), involved in the last step of fatty acids biosynthesis, was heterologously expressed in different strains of microalgae [118,119]. In Dunaliella tertiolecta, a combinational expression platform involving plant lauric acid-TE (C12TE) and medium-chain fatty acid-specific ketoacyl-ACP synthase was recently engineered, and resulted in a significant increase in lauric acid (C12:0) and myristic acid (C14:0) accumulation [120].

In addition to the strategies for increasing lipid production, fatty acid desaturation could be regulated in order to modify the PUFAs profile, by engineering either the desaturase/elongase pathway or the polyketide synthase pathway [121]. Both endogenous and exogenous desaturases and elongases have been successfully over-expressed in different oleaginous microalgae such as N. oceanica and P. tricornutum [122-124]. In Chlamydomonas, over-expression of the endogenous $\mathrm{Cr} \triangle 4 \mathrm{FAD}$, a monogalactosyl-diacylglycerol $\Delta 4$-desaturase, resulted in increased production of the specific product hexadeca-4,7,10,13-tetraenoicacid (16:4) [125].

Microalgal lipid composition differs among species, moreover it is further affected by the cultivation conditions. The main storage lipids in oleaginous microalgae are triacylglycerols (TAG), which are more desirable for commercial-scale biodiesel processing than polar lipids or free fatty acids [126,127]. The first step of TAG biosynthesis is catalysed by acyl-CoA: glycerol-3-phosphate acyl-transferase, whose over-expression in P. tricornutum was shown to promote the formation of oil bodies, and led to a significant increase in lipid content $[128,129]$. A significant increase in lipid productivity was also obtained by up-regulating endogenous lysophosphatidic acid acyltransferase (LPAAT) both in C. reinhardtii and in P. tricornutum, and by over-expressing the Brassica napus LPAAT isoform in Chlamydomonas [130-132]. An additional rate-limiting steps in the TAG biosynthesis of microalgae is catalysed by chloroplastic (DGAT1) and ER (DGAT2) isoforms of diacylglycerol acyltransferase (DGAT) [133]. Over-expression of DGAT1/DGAT2 in P. tricornutum and Nannochloropsis spp. resulted in a significant increase of total lipid accumulation [128,134-136].

Other enzymes which have been targeted by genetic engineering approaches, and which have succeeded in improving TAG content, included that which was involved in acetyl-CoA synthesis: (i) the E. coli isoform of ACS (acetyl-CoA synthetase) was introduced in Schizochyrium [137]; (ii) PDC (pyruvate dehydrogenase complex) abundance was increased by down-regulating pyruvate dehydrogenase kinase (PDK) in P. tricornutum [138]; malic enzyme (ME) and glucose-6-phosphate dehydrogenase (G6PDH) were over-expressed in P. tricornutum [139,140].

In addition to the modification of fatty acid biosynthesis, competitive pathways e.g., starch synthesis have also been manipulated for generating wider metabolic changes [141]. The conversion of phosphoenolpyruvate (PEP) to oxaloacetate by PEPC (PEP carboxylase) preferentially diverts the carbon flow towards protein synthesis, and indeed PEPC down-regulation resulted in the over-expression of pyruvate kinase, which increased the levels of pyruvate and acetyl-CoA [142]. On the other hand, knock-down of a PEPC isoform by either artificial microRNA-mediated technology and CRISPRi in Chlamydomonas, and by RNAi in P. tricornutum, resulted in higher TAG accumulation [112,143,144].

Another strategy to improve TAG production is the inhibition of specific lipases. In Nannochloropsis oceanica the TAG lipases mutants $\operatorname{tgl1}$ and $\operatorname{tgl1} 2$ increased the TAG content by two-fold in early log phase cells [145]. 
Transcription factors represent a suitable target to be manipulated as an alternative to structural genes, since they proved to be more effective for inducing global metabolic changes. Several transcription factors controlling lipid biosynthetic pathways have been identified, and their over-expression resulted into more productive strains. The up-regulation of a Dof-type transcription factor in Chlamydomonas doubled the cellular content of TAG [146,147]. Over-expression of bZIP and bHLH transcription factors in both $N$. salina and N. oceanica improved biomass and lipid productivity [148-151]. In N. gaditana, 20 putative regulators of lipid production, down-regulated by nitrogen deprivation, were identified by RNA-seq; a strategy of selective knock-out by the Crispr-Cas 9 system allowed us to identify a homolog of the fungal $\mathrm{Zn}(\mathrm{II})_{2} \mathrm{Cys}_{6}$-encoding gene, which triggered lipid biosynthesis in Nannochloropsis and resulted in a 200\% increase of C partition to lipids, without significantly affecting the growth rate [152]. More recently, a Myb-like transcription factor Phosphorus Starvation Response (PtPSR) was identified in P. tricornutum; its modulation might represent a good strategy to enhance cell growth and TAG production in limited-phosphorous conditions [153]. A MYB DNA binding protein involved in cell cycle regulation was instead targeted in Chlamydomonas, showing that the mutants devoid of CrCDC5 accumulate more oil and starch with respect to WT [154].

Integrated, multiomic analysis has been recently performed on different high-lipid productive microalgal strains, in order to pinpoint a range of candidate molecular targets, aimed to enhance oil productivity in different growth conditions $[155,156]$.

\subsection{Endogenous Up-Regulation and Heterologous Expression of Isoprenoid Biosynthetic Pathways in Microalgae}

The photoautotrophic nature of microalgae requires the generation of isoprenoids, natural hydrocarbons associated with the photosynthetic apparatus (e.g., carotenoids, plastoquinon, phytol chains) and participating in photon capture and electron transport events. Thus, microalgae own specific isoprenoid biosynthetic pathways that could be manipulated by genetic engineering to increase the natural capacities for the generation of isoprenoids, or to promote heterologous isoprenoid production. These class of molecules, due to their intensive color, fragrance and antioxidant properties, are in high demand for various applications in animal feed, medicines and nutraceuticals, pest control agents, cosmetics and pigments [157].

Regarding the endogenous isoprenoids, carotenoids represent commercially successful products from microalgae: $\beta$-carotene from $D$. salina and astaxanthin from $H$. pluvialis are high-price products mainly used in aquaculture, and as food colouring agents and nutraceuticals [158]. As for zeaxanthin, hyper-accumulating $D$. salina strains were identified [159], while a $\triangle$ ZEP Chlamydomonas strain with a far higher zeaxanthin content than WT (56-fold) was shown to have a commercial potential in the production of eggs fortified with carotenoids $[83,160]$. In H. pluvialis, the endogenous phytoene desaturase was modified by site-directed mutagenesis, enhancing both the resistance to the herbicide norflurazon and the astaxanthin productivity [161]. Significant enhancements in carotenoid productivity were obtained by either over-expressing the $\beta$-carotene ketolase or expressing the endogenous phytoene desaturase in the chloroplast under the control of the psbA promoter [162,163].

In Chlamydomonas, the over-expression of C. zofingiensis ZEP resulted in an astaxanthin production, reaching values of $0.5 \mathrm{mg} \mathrm{g}^{-1} \mathrm{DW}$ [164]. To increase the production of fucoxanthin, employed as an antioxidant agent, the 1-deoxy-d-xylulose 5-phosphate synthase and the phytoene synthase were over-expressed in Phaeodacthylum [165].

Two pathways lead to synthesis isoprenoid products: The 2-c-methyl-D-erythritol 4-phosphate/1 deoxy-D-xylulose 5-phosphate (MEP/DOXP) pathway and the mevalonate pathway (MVA). These are localized in different cell compartments but generate the same 5-C precursors, isopentenyl diphosphate (IPP) and dimethylallyl diphosphate (DMAPP). The MVA pathway was lost during evolution in the Chlorophyta and Eustigmatophyceae [166], while it was conserved in other microalgae, e.g., P. Tricornutum maintained the cytosolic MVA pathway, thus representing a choice species for isoprenoid engineering and heterologous terpenoid production $[157,166]$. 
In Phaeodacthylum, lupeol synthase isoforms from A. thaliana and L. japonicus were expressed to produce lupeol, an anti-inflammatory triterpene [157]. Moreover, co-expression in the diatom of CYP716A12 from M. truncatula and its corresponding reductase MtCPR, was aimed to further functionalize lupeol in betulin for the production of the antiretroviral, antimalarial agent betulinic acid [157]. In Chlamydomonas, the fragrance patchoulol was produced by expressing the patchoulol synthase from Pogostemon cablin [167], while the synthesis of bisabolene, a sesquiterpene compound identified as a promising jet fuel candidate, resulted by both over-expressing the bisabolene synthase from Abies grandis and down-regulating both the geranylgeranyl diphosphate (GGPP) synthase and the squalene synthase [168].

Finally, several non-native diterpenoids were successfully produced in C. reinhardtii, by the heterologous expression of diterpene synthases targeted to the algal chloroplast, to convert native GGPP into the diterpenoid products casbene, taxadiene and 13R(+) manoyl oxide [169].

Notably, besides diatoms and green microalgae, Cyanobacteria represent the most targeted photosynthetic organisms for isoprenoid production, especially terpenoids [170]. Cyanobacteria are, indeed, promising platforms for biofuel production [171], and the knowledge on isoprenoid biosynthetic pathways regulation is instrumental in over-expressing key enzymes toward a higher productivity. To enhance isoprene synthesis, different plant isoprene synthase (IS) genes were expressed in Synechococcus elongatus, in particular the IS from Eucalyptus globulus was responsible for the most significant productivity enhancement among the isoforms tested [172]. Moreover, limonene is a terpenoid evaluated as a promising alternative fuel. The limonene synthase from Mentha spicata was successfully expressed in different species such as Synechococcus elongatus PCC 7942, Synechocystis sp. PCC 6803 and Synechococcus sp. PCC 7002 [173-175].

\section{Concluding Remarks}

Nowadays the technical advance in genetic engineering made it possible to engineer algal strains for enhancing both biomass productivity and the yield of high value products from microalgae. The major efforts are focused on obtaining strains with higher photosynthetic efficiency in order to decrease the unitary cost of algal biomass. The best results have been obtained by enhancing the homogeneity of light distribution within photobioreactors [82] and by decreasing their susceptibility to photodamage [89]. Besides the obvious strategy of targeting antenna systems, photoprotection was also enhanced by increasing photochemical quenching by boosting $\mathrm{CO}_{2}$ fixation through over-expressing RuBisCO activity, and other rate-liming enzymes in the CBB cycle [109].

Besides productivity, microalgae exploitation targets high value compounds. First, oleaginous strains, especially diatoms, were engineered to optimize the fatty acid chain-length profile for biodiesel production [141]. Secondly, isoprenoid biosynthesis pathway has been engineered to redirect carbon flux towards specific and high values products for chemical industry and/or as biofuels [176].

While the overall strategies have been well defined, limitations derive mainly from the low number of species that can be engineered to some extent besides the model species Chlamydomonas reinhardtii and the efficiency of the expression of the transgenes in different species [177].

Author Contributions: V.V. and S.B. identified patterns and trends in the literature, designed the structure of the review and prepared the tables and figures. R.B. and L.D. advised and directed the drafting process. All the authors contributed to searching for relevant literature and carried out a critical analysis of the literature discussed together and wrote the manuscript. All authors have read and agreed to the published version of the manuscript.

Funding: Financial support for this work was provided by the University of Verona (Fondo Ricerca di Base HuntingLight) and "Programma Operativo Regionale FSE 2014-2020" (Grant No. 1695-16-2216-2016) from Regione del Veneto.

Conflicts of Interest: The authors declare no conflict of interest. 


\section{References}

1. Barber, J. Photosynthetic energy conversion: Natural and artificial. Chem. Soc. Rev. 2009, 38, $185-196$. [CrossRef]

2. Stephenson, P.G.; Moore, C.M.; Terry, M.J.; Zubkov, M.V.; Bibby, T.S. Improving photosynthesis for algal biofuels: Toward a green revolution. Trends Biotechnol. 2011, 29, 615-623. [CrossRef] [PubMed]

3. Benedetti, M.; Vecchi, V.; Barera, S.; Dall'Osto, L. Biomass from microalgae: The potential of domestication towards sustainable biofactories. Microb. Cell Fact. 2018, 17, 173. [CrossRef] [PubMed]

4. Georgianna, D.R.; Stephen, P. Exploiting diversity and synthetic biology for the production of algal biofuels. Nature 2012, 488, 329-335. [CrossRef] [PubMed]

5. Melis, A. Solar energy conversion efficiencies in photosynthesis: Minimizing the chlorophyll antennae to maximize efficiency. Plant Sci. 2009, 177, 272-280. [CrossRef]

6. Guiry, M.D. How many species of algae are there? J. Phycol. 2012, 48, 1057-1063. [CrossRef]

7. Harris, E.H. Chlamydomonas as a model organism. Annu. Rev. Plant Physiol. Plant Mol. Biol. 2001, 52, 363-406. [CrossRef]

8. Grossman, A.R. Chlamydomonas reinhardtii and photosynthesis: Genetics to genomics. Curr. Opin. Plant Biol. 2000, 3, 132-137. [CrossRef]

9. Ip, P.F.; Chen, F. Production of astaxanthin by the green microalga Chlorella zofingiensis in the dark. Process Biochem. 2005, 40, 733-738. [CrossRef]

10. García, J.L.; de Vicente, M.; Galán, B. Microalgae, old sustainable food and fashion nutraceuticals. Microb. Biotechnol. 2017, 10, 1017-1024. [CrossRef]

11. Guccione, A.; Biondi, N.; Sampietro, G.; Rodolfi, L.; Bassi, N.; Tredici, M.R. Chlorella for protein and biofuels: From strain selection to outdoor cultivation in a Green Wall Panel photobioreactor. Biotechnol. Biofuels 2014, 7, 1-12. [CrossRef] [PubMed]

12. Cazzaniga, S.; Dall'Osto, L.; Szaub, J.; Scibilia, L.; Ballottari, M.; Purton, S.; Bassi, R. Domestication of the green alga Chlorella sorokiniana: Reduction of antenna size improves light-use efficiency in a photobioreactor. Biotechnol. Biofuels 2014, 7, 157. [CrossRef] [PubMed]

13. Xu, Y.; Ibrahim, I.; Wosu, C.; Ben-Amotz, A.; Harvey, P. Potential of New Isolates of Dunaliella Salina for Natural $\beta$-Carotene Production. Biology 2018, 7, 14. [CrossRef] [PubMed]

14. Ahmed, R.A.; He, M.; Aftab, R.A.; Zheng, S.; Nagi, M.; Bakri, R.; Wang, C. Bioenergy application of Dunaliella salina SA 134 grown at various salinity levels for lipid production. Sci. Rep. 2017, 7, 8118. [CrossRef]

15. Shah, M.M.R.; Liang, Y.; Cheng, J.J.; Daroch, M. Astaxanthin-Producing Green Microalga Haematococcus pluvialis: From Single Cell to High Value Commercial Products. Front. Plant Sci. 2016, 7, 531. [CrossRef]

16. Basso, S.; Simionato, D.; Gerotto, C.; Segalla, A.; Giacometti, G.M.; Morosinotto, T. Characterization of the photosynthetic apparatus of the Eustigmatophycean Nannochloropsis gaditana: Evidence of convergent evolution in the supramolecular organization of photosystem i. Biochim. Biophys. Acta-Bioenerg. 2014, 1837, 306-314. [CrossRef]

17. Simionato, D.; Block, M.A.; La Rocca, N.; Jouhet, J.; Maréchal, E.; Finazzi, G.; Morosinotto, T. The response of Nannochloropsis gaditana to nitrogen starvation includes de novo biosynthesis of triacylglycerols, a decrease of chloroplast galactolipids, and reorganization of the photosynthetic apparatus. Eukaryot. Cell 2013, 12, 665-676. [CrossRef]

18. Bowler, C.; Allen, A.E.; Badger, J.H.; Grimwood, J.; Jabbari, K.; Kuo, A.; Maheswari, U.; Martens, C.; Maumus, F.; Otillar, R.P.; et al. The Phaeodactylum genome reveals the evolutionary history of diatom genomes. Nature 2008, 456, 239-244. [CrossRef] [PubMed]

19. Wang, W.; Yu, L.-J.; Xu, C.; Tomizaki, T.; Zhao, S.; Umena, Y.; Chen, X.; Qin, X.; Xin, Y.; Suga, M.; et al. Structural basis for blue-green light harvesting and energy dissipation in diatoms. Science 2019, 363, eaav0365. [CrossRef] [PubMed]

20. Nelson, N.; Yocum, C.F. Structure and function of photosystem I and II. Annu. Rev. Plant Biol. 2006, 57, 521-565. [CrossRef] [PubMed]

21. Munekage, Y.; Hashimoto, M.; Miyake, C.; Tomizawa, K.; Endo, T.; Tasaka, M.; Shikanai, T. Cyclic electron flow around photosystem I is essential for photosynthesis. Nature 2004, 429, 579-582. [CrossRef] [PubMed] 
22. Jans, F.; Mignolet, E.; Houyoux, P.-A.; Cardol, P.; Ghysels, B.; Cuine, S.; Cournac, L.; Peltier, G.; Remacle, C.; Franck, F. A type II NAD(P)H dehydrogenase mediates light-independent plastoquinone reduction in the chloroplast of Chlamydomonas. Proc. Natl. Acad. Sci. USA 2008, 105, 20546-20551. [CrossRef]

23. Jokel, M.; Johnson, X.; Peltier, G.; Aro, E.M.; Allahverdiyeva, Y. Hunting the main player enabling Chlamydomonas reinhardtii growth under fluctuating light. Plant. J. 2018, 94, 822-835. [CrossRef]

24. Dall'Osto, L.; Bressan, M.; Bassi, R. Biogenesis of light harvesting proteins. Biochim. Biophys. Acta-Bioenerg. 2015, 1847, 861-871. [CrossRef]

25. Ballottari, M.; Girardon, J.; Dall'Osto, L.; Bassi, R. Evolution and functional properties of Photosystem II light harvesting complexes in eukaryotes. Biochim. Biophys. Acta-Bioenerg. 2012, 1817, 143-157. [CrossRef] [PubMed]

26. Liu, Z.; Yan, H.; Wang, K.; Kuang, T.; Zhang, J.; Gui, L.; An, X.; Chang, W. Crystal structure of spinach major light-harvesting complex at 2.72 A resolution. Nature 2004, 428, 287-292. [CrossRef] [PubMed]

27. Ben-Shem, A.; Frolow, F.; Nelson, N. Crystal structure of plant photosystem I. Nature 2003, 426, 630-635. [CrossRef] [PubMed]

28. Dall'Osto, L.; Piques, M.; Ronzani, M.; Molesini, B.; Alboresi, A.; Cazzaniga, S.; Bassi, R. The Arabidopsis nox mutant lacking carotene hydroxylase activity reveals a critical role for xanthophylls in photosystem I biogenesis. Plant Cell 2013, 25, 591-608. [CrossRef]

29. Rochaix, J.-D.; Bassi, R. LHC-like proteins involved in stress responses and biogenesis/repair of the photosynthetic apparatus. Biochem. J. 2019, 476, 581-593. [CrossRef]

30. Alboresi, A.; Caffarri, S.; Nogue, F.; Bassi, R.; Morosinotto, T. In Silico and Biochemical Analysis of Physcomitrella patens Photosynthetic Antenna: Identification of Subunits which Evolved upon Land Adaptation. PLoS ONE 2008, 3, e2033. [CrossRef]

31. Peers, G.; Truong, T.B.; Ostendorf, E.; Busch, A.; Elrad, D.; Grossman, A.R.; Hippler, M.; Niyogi, K.K. An ancient light-harvesting protein is critical for the regulation of algal photosynthesis. Nature 2009, 462, 518-521. [CrossRef] [PubMed]

32. Miloslavina, Y.; de Bianchi, S.; Dall'Osto, L.; Bassi, R.; Holzwarth, A.R. Quenching in Arabidopsis thaliana Mutants Lacking Monomeric Antenna Proteins of Photosystem II. J. Biol. Chem. 2011, 286, 36830-36840. [CrossRef] [PubMed]

33. Su, X.; Ma, J.; Wei, X.; Cao, P.; Zhu, D.; Chang, W.; Liu, Z.; Zhang, X.; Li, M. Structure and assembly mechanism of plant C2S2M2-type PSII-LHCII supercomplex. Science (80-) 2017, 357, 815-820. [CrossRef] [PubMed]

34. Drop, B.; Webber-Birungi, M.; Yadav, S.K.N.; Filipowicz-Szymanska, A.; Fusetti, F.; Boekema, E.J.; Croce, R. Light-harvesting complex II (LHCII) and its supramolecular organization in Chlamydomonas reinhardtii. Biochim. Biophys. Acta-Bioenerg. 2014, 1837, 63-72. [CrossRef]

35. Shen, L.; Huang, Z.; Chang, S.; Wang, W.; Wang, J.; Kuang, T.; Han, G.; Shen, J.-R.; Zhang, X. Structure of a C2S2M2N2-type PSII-LHCII supercomplex from the green alga Chlamydomonas reinhardtii. Proc. Natl. Acad. Sci. USA 2019, 2019, 12462. [CrossRef] [PubMed]

36. Drop, B.; Webber-birungi, M.; Fusetti, F.; Kour, R.; Redding, K.E.; Boekema, E.J.; Croce, R. Photosystem I of Chlamydomonas reinhardtii Contains Nine Light-harvesting Complexes (Lhca) Located on One Side of the core. J. Biol. Chem. 2011, 286, 44878-44887. [CrossRef]

37. Steinbeck, J.; Ross, I.L.; Rothnagel, R.; Gäbelein, P.; Schulze, S.; Giles, N.; Ali, R.; Drysdale, R.; Sierecki, E.; Gambin, Y.; et al. Structure of a PSI-LHCI-cyt b6f supercomplex in Chlamydomonas reinhardtii promoting cyclic electron flow under anaerobic conditions. Proc. Natl. Acad. Sci. USA 2018, 115, 10517-10522. [CrossRef]

38. Su, X.; Ma, J.; Pan, X.; Zhao, X.; Chang, W.; Liu, Z.; Zhang, X.; Li, M. Antenna arrangement and energy transfer pathways of a green algal photosystem-I-LHCI supercomplex. Nat. Plants 2019, 5, 273-281. [CrossRef]

39. Harrison, E.P.; Willingham, N.M.; Lloyd, J.C.; Raines, C.A. Reduced sedoheptulose-1,7-bisphosphatase levels in transgenic tobacco lead to decreased photosynthetic capacity and altered carbohydrate accumulation. Planta 1997, 204, 27-36. [CrossRef]

40. Curmi, P.M.; Cascio, D.; Sweet, R.M.; Eisenberg, D.; Schreuder, H. Crystal structure of the unactivated form of ribulose-1,5-bisphosphate carboxylase/oxygenase from tobacco refined at 2.0-A resolution. J. Biol. Chem. 1992, 267, 16980-16989. 
41. Newman, J.; Branden, C.I.; Jones, T.A. Structure determination and refinement of ribulose 1,5-bisphosphate carboxylase/oxygenase from Synechococcus PCC6301. Acta Crystallogr. D Biol. Crystallogr. 1993, 49, 548-560. [CrossRef] [PubMed]

42. Taylor, T.C.; Backlund, A.; Bjorhall, K.; Spreitzer, R.J.; Andersson, I. First crystal structure of Rubisco from a green alga, Chlamydomonas reinhardtii. J. Biol. Chem. 2001, 276, 48159-48164. [CrossRef] [PubMed]

43. Uemura, K.; Miyachi, S.; Yokota, A. Ribulose-1,5-Bisphosphate Carboxylase/Oxygenase from Thermophilic Red Algae with a Strong Specificity for CO 2 Fixation. Biochem. Biophys. Res. Commun. 1997, 571, 568-571. [CrossRef] [PubMed]

44. Kuchitsu, K.; Tsuzuki, M.; Miyachi, S. Polypeptide composition and enzyme activities of the pyrenoid and its regulation by CO2 concentration in unicellular green algae. Can. J. Bot. 1991, 69, 1062-1069. [CrossRef]

45. Ryan, P.; Forrester, T.J.B.; Wroblewski, C.; Kenney, T.M.G.; Kitova, E.N.; Klassen, J.S.; Kimber, M.S. The small $\mathrm{RbcS}$-like domains of the $\beta$-carboxysome structural protein $\mathrm{CcmM}$ bind RubisCO at a site distinct from that binding the RbcS subunit. J. Biol. Chem. 2019, 294, 2593-2603. [CrossRef] [PubMed]

46. Horton, P.; Ruban, A.V.; Walters, R.G. Regulation of Light Harvesting In Green Plants. Annu. Rev. Plant Physiol. Plant Mol. Biol. 1996, 47, 655-684. [CrossRef]

47. Allorent, G.; Tokutsu, R.; Roach, T.; Peers, G.; Cardol, P.; Girard-Bascou, J.; Seigneurin-Berny, D.; Petroutsos, D.; Kuntz, M.; Breyton, C.; et al. Dual strategy to cope with high light in Chlamydomonas reinhardtii. Plant Cell 2013, 25, 545-557. [CrossRef]

48. Dall'Osto, L.; Caffarri, S.; Bassi, R. A mechanism of nonphotochemical energy dissipation, independent from PsbS, revealed by a conformational change in the antenna protein CP26. Plant Cell 2005, 17, 1217-1232. [CrossRef]

49. Quaas, T.; Berteotti, S.; Ballottari, M.; Flieger, K.; Bassi, R.; Wilhelm, C.; Goss, R. Non-photochemical quenching and xanthophyll cycle activities in six green algal species suggest mechanistic differences in the process of excess energy dissipation. J. Plant Physiol. 2015, 172, 92-103. [CrossRef]

50. Alboresi, A.; Gerotto, C.; Giacometti, G.M.; Bassi, R.; Morosinotto, T. Physcomitrella patens mutants affected on heat dissipation clarify the evolution of photoprotection mechanisms upon land colonization. Proc. Natl. Acad. Sci. USA 2010, 107, 11128-11133. [CrossRef]

51. Li, X.-P.; Björkman, O.; Shih, C.; Grossman, A.R.; Rosenquist, M.; Jansson, S.; Niyogi, K.K. A pigment-binding protein essential for regulation of photosynthetic light harvesting. Nature 2000, 403, 391-395. [CrossRef] [PubMed]

52. Fan, M.; Li, M.; Liu, Z.; Cao, P.; Pan, X.; Zhang, H.; Zhao, X.; Zhang, J.; Chang, W. Crystal structures of the PsbS protein essential for photoprotection in plants. Nat. Struct. AMP Mol. Biol. 2015, 22, 729. [CrossRef] [PubMed]

53. Li, X.-P.; Gilmore, A.M.; Caffarri, S.; Bassi, R.; Golan, T.; Kramer, D.; Niyogi, K.K. Regulation of Photosynthetic Light Harvesting Involves Intrathylakoid Lumen pH Sensing by the PsbS Protein. J. Biol. Chem. 2004, 279, 22866-22874. [CrossRef] [PubMed]

54. Ballottari, M.; Truong, T.B.; De Re, E.; Erickson, E.; Stella, G.R.; Fleming, G.R.; Bassi, R.; Niyogi, K.K. Identification of $\mathrm{pH}$-sensing Sites in the Light Harvesting Complex Stress-related 3 Protein Essential for Triggering Non-photochemical Quenching in Chlamydomonas reinhardtii. J. Biol. Chem. 2016, 291, 7334-7346. [CrossRef]

55. Gabilly, S.T.; Baker, C.R.; Wakao, S.; Crisanto, T.; Guan, K.; Bi, K.; Guiet, E.; Guadagno, C.R.; Niyogi, K.K. Regulation of photoprotection gene expression in Chlamydomonas by a putative E3 ubiquitin ligase complex and a homolog of CONSTANS. Proc. Natl. Acad. Sci. USA 2019, 116, 11556-11562. [CrossRef]

56. Petroutsos, D.; Busch, A.; Janssen, I.; Trompelt, K.; Bergner, S.V.; Weinl, S.; Holtkamp, M.; Karst, U.; Kudla, J.; Hippler, M. The chloroplast calcium sensor CAS is required for photoacclimation in Chlamydomonas reinhardtii. Plant Cell 2011, 23, 2950-2963. [CrossRef]

57. Pinnola, A.; Staleva-Musto, H.; Capaldi, S.; Ballottari, M.; Bassi, R.; Polívka, T. Electron transfer between carotenoid and chlorophyll contributes to quenching in the LHCSR1 protein from Physcomitrella patens. Biochim. Biophys. Acta-Bioenerg. 2016, 1857, 1870-1878. [CrossRef]

58. Kondo, T.; Pinnola, A.; Chen, W.J.; Dall'Osto, L.; Bassi, R.; Schlau-Cohen, G.S. Single-molecule spectroscopy of LHCSR1 protein dynamics identifies two distinct states responsible for multi-timescale photosynthetic photoprotection. Nat. Chem. 2017, 9, 772. [CrossRef] 
59. Kondo, T.; Gordon, J.B.; Pinnola, A.; Dall'Osto, L.; Bassi, R.; Schlau-Cohen, G.S. Microsecond and millisecond dynamics in the photosynthetic protein LHCSR1 observed by single-molecule correlation spectroscopy. Proc. Natl. Acad. Sci. USA 2019, 2018, 21207. [CrossRef]

60. Ahn, T.K.; Avenson, T.J.; Ballottari, M.; Cheng, Y.-C.; Niyogi, K.K.; Bassi, R.; Fleming, G.R. Architecture of a Charge-Transfer State Regulating Light Harvesting in a Plant Antenna Protein. Science (80-) 2008, 320, 794-797. [CrossRef]

61. Holt, N.E.; Zigmantas, D.; Valkunas, L.; Li, X.-P.; Niyogi, K.K.; Fleming, G.R. Carotenoid Cation Formation and the Regulation of Photosynthetic Light Harvesting. Science (80-) 2005, 307, 433-436. [CrossRef] [PubMed]

62. Bonente, G.; Ballottari, M.; Truong, T.B.; Morosinotto, T.; Ahn, T.K.; Fleming, G.R.; Niyogi, K.K.; Bassi, R. Analysis of LhcSR3, a Protein Essential for Feedback De-Excitation in the Green Alga Chlamydomonas reinhardtii. PLoS Biol. 2011, 9, e1000577. [CrossRef] [PubMed]

63. Fuciman, M.; Enriquez, M.M.; Polívka, T.; Dall'Osto, L.; Bassi, R.; Frank, H.A. Role of Xanthophylls in Light Harvesting in Green Plants: A Spectroscopic Investigation of Mutant LHCII and Lhcb Pigment-Protein Complexes. J. Phys. Chem. B 2012, 116, 3834-3849. [CrossRef] [PubMed]

64. Ruban, A.V.; Berera, R.; Ilioaia, C.; van Stokkum, I.H.M.; Kennis, J.T.M.; Pascal, A.A.; van Amerongen, H.; Robert, B.; Horton, P.; van Grondelle, R. Identification of a mechanism of photoprotective energy dissipation in higher plants. Nature 2007, 450, 575. [CrossRef]

65. Li, Z.; Peers, G.; Dent, R.M.; Bai, Y.; Yang, S.Y.; Apel, W.; Leonelli, L.; Niyogi, K.K. Evolution of an atypical de-epoxidase for photoprotection in the green lineage. Nat. Plants 2016, 2, 16140. [CrossRef]

66. Niyogi, K.K. PHOTOPROTECTION REVISITED: Genetic and Molecular Approaches. Annu. Rev. Plant Physiol. Plant Mol. Biol. 1999, 50, 333-359. [CrossRef]

67. Shapiguzov, A.; Chai, X.; Fucile, G.; Longoni, P.; Zhang, L.; Rochaix, J.D. Activation of the Stt7/STN7 Kinase through dynamic interactions with the cytochrome b6 f complex. Plant Physiol. 2016, 171, 82-92. [CrossRef]

68. Gilmore, A.M.; Ball, M.C. Protection and storage of chlorophyll in overwintering evergreens. Proc. Natl. Acad. Sci. USA 2000. [CrossRef]

69. Anderson, J.M.; Chow, W.S.; Park, Y.-I. The grand design of photosynthesis: Acclimation of the photosynthetic apparatus to environmental cues. Photosynth. Res. 1995, 46, 129-139. [CrossRef]

70. Durnford, D.; Price, J.A.; McKim, S.M.; Sarchfield, M.L. Light-harvesting complex gene expression is controlled by both transcriptional and post-transcriptional mechanisms during photoacclimation in Chlamydomonas reinhardtii. Physiol. Plant. 2003, 118, 193-205. [CrossRef]

71. Escoubas, J.M.; Lomas, M.; LaRoche, J.; Falkowski, P.G. Light intensity regulation of cab gene transcription is signaled by the redox state of the plastoquinone pool. Proc. Natl. Acad. Sci. USA 1995, 92, 10237-10241. [CrossRef] [PubMed]

72. Bonente, G.; Pippa, S.; Castellano, S.; Bassi, R.; Ballottari, M. Acclimation of Chlamydomonas reinhardtii to different growth irradiances. J. Biol. Chem. 2012, 287, 5833-5847. [CrossRef] [PubMed]

73. Mettler, T.; Mühlhaus, T.; Hemme, D.; Schöttler, M.A.; Rupprecht, J.; Idoine, A.; Veyel, D.; Pal, S.K.; Yaneva-Roder, L.; Winck, F.V.; et al. Systems Analysis of the Response of Photosynthesis, Metabolism, and Growth to an Increase in Irradiance in the Photosynthetic Model Organism Chlamydomonas reinhardtii. Plant Cell 2014, 26, 2310-2350. [CrossRef] [PubMed]

74. Ballottari, M.; Dall'Osto, L.; Morosinotto, T.; Bassi, R. Contrasting Behavior of Higher Plant Photosystem I and II Antenna Systems during Acclimation. J. Biol. Chem. 2007, 282, 8947-8958. [CrossRef]

75. Ferrante, P.; Ballottari, M.; Bonente, G.; Giuliano, G.; Bassi, R. LHCBM1 and LHCBM2/7 polypeptides, components of major LHCII complex, have distinct functional roles in photosynthetic antenna system of Chlamydomonas reinhardtii. J. Biol. Chem. 2012, 287, 16276-16288. [CrossRef]

76. Elrad, D.; Niyogi, K.K.; Grossman, A.R. A Major Light-Harvesting Polypeptide of Photosystem II Functions in Thermal Dissipation. Plant Cell 2002, 14, 1801-1816. [CrossRef]

77. Grewe, S.; Ballottari, M.; Alcocer, M.; D’Andrea, C.; Blifernez-Klassen, O.; Hankamer, B.; Mussgnug, J.H.; Bassi, R.; Kruse, O. Light-Harvesting Complex Protein LHCBM9 Is Critical for Photosystem II Activity and Hydrogen Production in Chlamydomonas reinhardtii. Plant Cell 2014, 26, 1598-1611. [CrossRef]

78. Mussgnug, J.H.; Wobbe, L.; Elles, I.; Claus, C.; Hamilton, M.; Fink, A.; Kahmann, U.; Kapazoglou, A.; Mullineaux, C.W.; Hippler, M.; et al. NAB1 is an RNA binding protein involved in the light-regulated differential expression of the light-harvesting antenna of Chlamydomonas reinhardtii. Plant Cell 2005, 17, 3409-3421. [CrossRef] 
79. Polle, J.E.W.; Kanakagiri, S.-D.; Melis, A. tla1, a DNA insertional transformant of the green alga Chlamydomonas reinhardtii with a truncated light-harvesting chlorophyll antenna size. Planta 2003, 217, 49-59. [CrossRef]

80. Mitra, M.; Kirst, H.; Dewez, D.; Melis, A. Modulation of the light-harvesting chlorophyll antenna size in Chlamydomonas reinhardtii by TLA1 gene over-expression and RNA interference. Philos. Trans. R. Soc. B Biol. Sci. 2012, 367, 3430-3443. [CrossRef]

81. Kirst, H.; García-Cerdán, J.G.; Zurbriggen, A.; Melis, A. Assembly of the light-harvesting chlorophyll antenna in the green alga Chlamydomonas reinhardtii requires expression of the TLA2-CpFTSY gene. Plant Physiol. 2012, 158, 930-945. [CrossRef] [PubMed]

82. Kirst, H.; Melis, A. The chloroplast signal recognition particle (CpSRP) pathway as a tool to minimize chlorophyll antenna size and maximize photosynthetic productivity. Biotechnol. Adv. 2014, 32, 66-72. [CrossRef] [PubMed]

83. Baek, K.; Kim, D.H.; Jeong, J.; Sim, S.J.; Melis, A.; Kim, J.S.; Jin, E.; Bae, S. DNA-free two-gene knockout in Chlamydomonas reinhardtii via CRISPR-Cas9 ribonucleoproteins. Sci. Rep. 2016, 6, 30620. [CrossRef] [PubMed]

84. Jeong, J.; Baek, K.; Yu, J.; Kirst, H.; Betterle, N.; Shin, W.; Bae, S.; Melis, A.; Jin, E. Deletion of the chloroplast LTD protein impedes LHCI import and PSI-LHCI assembly in Chlamydomonas reinhardtii. J. Exp. Bot. 2018, 69, 1147-1158. [CrossRef]

85. Perin, G.; Bellan, A.; Segalla, A.; Meneghesso, A.; Alboresi, A.; Morosinotto, T. Generation of random mutants to improve light-use efficiency of Nannochloropsis gaditana cultures for biofuel production. Biotechnol. Biofuels 2015, 8, 161. [CrossRef]

86. Tanaka, A.; Ito, H.; Tanaka, R.; Tanaka, N.K.; Yoshida, K.; Okada, K. Chlorophyll a oxygenase (CAO) is involved in chlorophyll b formation from chlorophyll a. Proc. Natl. Acad. Sci. USA 1998, 95, 12719-12723. [CrossRef]

87. Bujaldon, S.; Kodama, N.; Rappaport, F.; Subramanyam, R.; de Vitry, C.; Takahashi, Y.; Wollman, F.A. Functional Accumulation of Antenna Proteins in Chlorophyll b-Less Mutants of Chlamydomonas reinhardtii. Mol. Plant 2017, 10, 115-130. [CrossRef]

88. Perrine, Z.; Negi, S.; Sayre, R.T. Optimization of photosynthetic light energy utilization by microalgae. Algal Res. 2012, 1, 134-142. [CrossRef]

89. Dall'Osto, L.; Cazzaniga, S.; Guardini, Z.; Barera, S.; Benedetti, M.; Mannino, G.; Maffei, M.E.; Bassi, R. Combined resistance to oxidative stress and reduced antenna size enhance light-to-biomass conversion efficiency in Chlorella vulgaris cultures. Biotechnol. Biofuels 2019, 12, 221. [CrossRef]

90. Kromdijk, J.; Głowacka, K.; Leonelli, L.; Gabilly, S.T.; Iwai, M.; Niyogi, K.K.; Long, S.P. Improving photosynthesis and crop productivity by accelerating recovery from photoprotection. Science (80-) 2016, 354, 857-861. [CrossRef]

91. Förster, B.; Osmond, C.B.; Pogson, B.J. Improved survival of very high light and oxidative stress is conferred by spontaneous gain-of-function mutations in Chlamydomonas. Biochim. Biophys. Acta-Bioenerg. 2005, 1709, 45-57. [CrossRef] [PubMed]

92. Fischer, B.B.; Ledford, H.K.; Wakao, S.; Huang, S.G.; Casero, D.; Pellegrini, M.; Merchant, S.S.; Koller, A.; Eggen, R.I.L.; Niyogi, K.K. Singlet Oxygen Resistant 1 links reactive electrophile signaling to singlet oxygen acclimation in Chlamydomonas reinhardtii. Proc. Natl. Acad. Sci. USA 2012, 109, E1302-E1311. [CrossRef] [PubMed]

93. Schierenbeck, L.; Ries, D.; Rogge, K.; Grewe, S.; Weisshaar, B.; Kruse, O. Fast forward genetics to identify mutations causing a high light tolerant phenotype in Chlamydomonas reinhardtii by whole-genome-sequencing. BMC Genom. 2015, 16, 57. [CrossRef] [PubMed]

94. Treves, H.; Raanan, H.; Finkel, O.M.; Berkowicz, S.M.; Keren, N.; Shotland, Y.; Kaplan, A. A newly isolated Chlorella sp. from desert sand crusts exhibits a unique resistance to excess light intensity. FEMS Microbiol. Ecol. 2013, 86, 373-380. [CrossRef]

95. Treves, H.; Raanan, H.; Kedem, I.; Murik, O.; Keren, N.; Zer, H.; Berkowicz, S.M.; Giordano, M.; Norici, A.; Shotland, Y.; et al. The mechanisms whereby the green alga Chlorella ohadii, isolated from desert soil crust, exhibits unparalleled photodamage resistance. New Phytol. 2016, 210, 1229-1243. [CrossRef]

96. Whitney, S.M.; Houtz, R.L.; Alonso, H. Advancing Our Understanding and Capacity to Engineer Nature's $\mathrm{CO}_{2}$-Sequestering Enzyme, Rubisco. Plant Physiol. 2011, 155, 27-35. [CrossRef] 
97. Karkehabadi, S.; Peddi, S.R.; Anwaruzzaman, M.; Taylor, T.C.; Cederlund, A.; Genkov, T.; Andersson, I.; Spreitzer, R.J. Chimeric small subunits influence catalysis without causing global conformational changes in the crystal structure of ribulose-1,5-bisphosphate carboxylase/oxygenase. Biochemistry 2005, 44, 9851-9861. [CrossRef]

98. Genkov, T.; Meyer, M.; Griffiths, H.; Spreitzer, R.J. Functional Hybrid Rubisco Enzymes with Plant Small Subunits and Algal Large Subunits: Engineered rbcS cDNA for expression in Chlamydomonas. J. Biol. Chem. 2010, 285, 19833-19841. [CrossRef]

99. Larson, E.M.; O’Brien, C.M.; Zhu, G.; Spreitzer, R.J.; Portis, A.R. Specificity for activase is changed by a Pro-89 to Arg substitution in the large subunit of ribulose-1,5-bisphosphate carboxylase/oxygenase. J. Biol. Chem. 1997, 272, 17033-17037. [CrossRef]

100. Ott, C.M.; Smith, B.D.; Portis, A.R.; Spreitzer, R.J. Activase region on chloroplast ribulose-1,5-bisphosphate carboxylase/oxygenase: Nonconservative substitution in the large subunit alters species specificity of protein interaction. J. Biol. Chem. 2000, 275, 26241-26244. [CrossRef]

101. Li, C.; Salvucci, M.E.; Portis, A.R. Two residues of Rubisco activase involved in recognition of the Rubisco substrate. J. Biol. Chem. 2005, 280, 24864-24869. [CrossRef] [PubMed]

102. Wei, L.; Wang, Q.; Xin, Y.; Lu, Y.; Xu, J. Enhancing photosynthetic biomass productivity of industrial oleaginous microalgae by overexpression of RuBisCO activase. Algal Res. 2017, 27, 366-375. [CrossRef]

103. Liang, F.; Lindblad, P. Synechocystis PCC 6803 overexpressing RuBisCO grow faster with increased photosynthesis. Metab. Eng. Commun. 2017, 4, 29-36. [CrossRef] [PubMed]

104. Ruffing, A.M. Improved Free Fatty Acid Production in Cyanobacteria with Synechococcus sp. PCC 7002 as Host. Front. Bioeng. Biotechnol. 2014, 2, 17. [CrossRef]

105. Zhu, G.; Kurek, I.; Liu, L. Chapter 20 Engineering Photosynthetic Enzymes Involved in CO2-Assimilation by Gene Shuffling BT-The Chloroplast: Basics and Applications; Rebeiz, C.A., Ed.; Springer: Berlin/Heidelberg, Germany, 2010; pp. 307-322. [CrossRef]

106. Pinto, T.S.; Malcata, F.X.; Arrabaça, J.D.; Silva, J.M.; Spreitzer, R.J.; Esquível, M.G. Rubisco mutants of Chlamydomonas reinhardtii enhance photosynthetic hydrogen production. Appl. Microbiol. Biotechnol. 2013, 97, 5635-5643. [CrossRef]

107. Wunder, T.; Cheng, S.L.H.; Lai, S.-K.; Li, H.-Y.; Mueller-Cajar, O. The phase separation underlying the pyrenoid-based microalgal Rubisco supercharger. Nat. Commun. 2018, 9, 5076. [CrossRef]

108. Fang, L.; Lin, H.X.; Low, C.S.; Wu, M.H.; Chow, Y.; Lee, Y.K. Expression of the Chlamydomonas reinhardtii Sedoheptulose-1,7-bisphosphatase in Dunaliella bardawil leads to enhanced photosynthesis and increased glycerol production. Plant Biotechnol. J. 2012, 10, 1129-1135. [CrossRef]

109. Liang, F.; Lindblad, P. Effects of overexpressing photosynthetic carbon flux control enzymes in the cyanobacterium Synechocystis PCC 6803. Metab. Eng. 2016, 38, 56-64. [CrossRef]

110. Liang, F.; Englund, E.; Lindberg, P.; Lindblad, P. Engineered cyanobacteria with enhanced growth show increased ethanol production and higher biofuel to biomass ratio. Metab. Eng. 2018, 46, 51-59. [CrossRef]

111. Spalding, M.H. Modulation of Low Carbon Dioxide Inducible Proteins (lci) for Increased Biomass Production and Photosynthesis. U.S. Patent Application No. 13/535,842, 3 January 2013.

112. Kao, P.H.; Ng, I.S. CRISPRi mediated phosphoenolpyruvate carboxylase regulation to enhance the production of lipid in Chlamydomonas reinhardtii. Bioresour. Technol. 2017, 245, 1527-1537. [CrossRef]

113. Courchesne, N.M.D.; Parisien, A.; Wang, B.; Lan, C.Q. Enhancement of lipid production using biochemical, genetic and transcription factor engineering approaches. J. Biotechnol. 2009, 141, 31-41. [CrossRef] [PubMed]

114. Leu, S.; Boussiba, S. Advances in the Production of High-Value Products by Microalgae. Ind. Biotechnol. 2014, 10, 169-183. [CrossRef]

115. Li, D.; Xie, W.; Hao, T.; Cai, J.; Zhou, T.; Balamurugan, S. Constitutive and Chloroplast Targeted Expression of Acetyl-CoA Carboxylase in Oleaginous Microalgae Elevates Fatty Acid Biosynthesis. Mar. Biotechnol. (NY) 2018, 20, 566-572. [CrossRef] [PubMed]

116. Chen, J.; Liu, W.; Hu, D.; Wang, X. Identification of a malonyl CoA-acyl carrier protein transacylase and its regulatory role in fatty acid biosynthesis in oleaginous microalga Nannochloropsis oceanica. Biotechnol. Appl. Biochem. 2017, 64, 620-626. [CrossRef]

117. Li, Z.; Meng, T.; Ling, X.; Li, J.; Zheng, C.; Shi, Y.; Chen, Z.; Li, Z.; Li, Q.; Lu, Y.; et al. Overexpression of Malonyl-CoA: ACP Transacylase in Schizochytrium sp. to Improve Polyunsaturated Fatty Acid Production. J. Agric. Food Chem. 2018, 66, 5382-5391. [CrossRef] 
118. Wei, K.; Tan, M.; Lee, Y.K. Expression of the heterologous Dunaliella tertiolecta fatty acyl-ACP thioesterase leads to increased lipid production in Chlamydomonas reinhardtii. J. Biotechnol. 2017, 247, 60-67.

119. Radakovits, R.; Eduafo, P.M.; Posewitz, M.C. Genetic engineering of fatty acid chain length in Phaeodactylum tricornutum. Metab. Eng. 2011, 13, 89-95. [CrossRef]

120. Lin, H.; Lee, Y.K. Genetic engineering of medium-chain-length fatty acid synthesis in Dunaliella tertiolecta for improved biodiesel production. J. Appl. Phycol. 2017, 29, 2811-2819. [CrossRef]

121. Napier, J.A. Plumbing the depths of PUFA biosynthesis: A novel polyketide synthase-like pathway from marine organisms. Trends Plant Sci. 2002, 7, 51-54. [CrossRef]

122. Kaye, Y.; Grundman, O.; Leu, S.; Zarka, A.; Zorin, B.; Didi-Cohen, S.; Khozin-Goldberg, I.; Boussiba, S. Metabolic engineering toward enhanced LC-PUFA biosynthesis in Nannochloropsis oceanica: Overexpression of endogenous $\Delta 12$ desaturase driven by stress-inducible promoter leads to enhanced deposition of polyunsaturated fatty acids in TAG. Algal Res. 2015, 11, 387-398. [CrossRef]

123. Hamilton, M.L.; Haslam, R.P.; Napier, J.A.; Sayanova, O. Metabolic engineering of Phaeodactylum tricornutum for the enhanced accumulation of omega-3 long chain polyunsaturated fatty acids. Metab. Eng. 2014, 22, 3-9. [CrossRef] [PubMed]

124. Peng, K.-T.; Zheng, C.-N.; Xue, J.; Chen, X.-Y.; Yang, W.-D.; Liu, J.-S.; Bai, W.; Li, H.-Y. Delta 5 Fatty Acid Desaturase Upregulates the Synthesis of Polyunsaturated Fatty Acids in the Marine Diatom Phaeodactylum tricornutum. J. Agric. Food Chem. 2014, 62, 8773-8776. [CrossRef]

125. Zäuner, S.; Jochum, W.; Bigorowski, T.; Benning, C. A cytochrome b5-containing plastid-located fatty acid desaturase from Chlamydomonas reinhardtii. Eukaryot. Cell 2012, 11, 856-863. [CrossRef] [PubMed]

126. Liang, M.; Jiang, J. Progress in Lipid Research Advancing oleaginous microorganisms to produce lipid via metabolic engineering technology. Prog. Lipid Res. 2013, 52, 395-408. [CrossRef] [PubMed]

127. Halim, R.; Danquah, M.K.; Webley, P.A. Extraction of oil from microalgae for biodiesel production: A review. Biotechnol. Adv. 2012, 30, 709-732. [CrossRef] [PubMed]

128. Zou, L.G.; Chen, J.W.; Zheng, D.L.; Balamurugan, S.; Li, D.W.; Yang, W.D.; Liu, J.S. High-efficiency promoter-driven coordinated regulation of multiple metabolic nodes elevates lipid accumulation in the model microalga Phaeodactylum tricornutum. Microb. Cell Fact. 2018, 17, 54. [CrossRef]

129. Niu, Y.F.; Wang, X.; Hu, D.X.; Balamurugan, S.; Li, D.W. Molecular characterization of a glycerol-3-phosphate acyltransferase reveals key features essential for triacylglycerol production in Phaeodactylum tricornutum. Biotechnol. Biofuels 2016, 9, 60. [CrossRef]

130. Yamaoka, Y.; Achard, D.; Jang, S.; Leg, B.; Kamisuki, S.; Ko, D.; Schulz-raffelt, M.; Kim, Y.; Song, W.; Nishida, I.; et al. Identification of a Chlamydomonas plastidial 2-lysophosphatidic acid acyltransferase and its use to engineer microalgae with increased oil content. Plant Biotechnol. J. 2016, 14, 2158-2167. [CrossRef]

131. Balamurugan, S.; Wang, X.; Wang, H.-L.; An, C.-J.; Li, H.; Li, D.-W.; Yang, W.-D.; Liu, J.-S.; Li, H.-Y. Occurrence of plastidial triacylglycerol synthesis and the potential regulatory role of AGPAT in the model diatom Phaeodactylum tricornutum. Biotechnol. Biofuels 2017, 10, 97. [CrossRef]

132. Wang, C.; Li, Y.; Lu, J.; Deng, X.; Li, H.; Hu, Z. Effect of overexpression of LPAAT and GPD1 on lipid synthesis and composition in green microalga Chlamydomonas reinhardtii. J. Appl. Phycol. 2018, 30, 1711-1719. [CrossRef]

133. Cases, S.; Smith, S.J.; Zheng, Y.W.; Myers, H.M.; Lear, S.R.; Sande, E.; Novak, S.; Collins, C.; Welch, C.B.; Lusis, A.J.; et al. Identification of a gene encoding an acyl CoA: Diacylglycerol acyltransferase, a key enzyme in triacylglycerol synthesis. Proc. Natl. Acad. Sci. USA 1998, 95, 13018-13023. [CrossRef] [PubMed]

134. Cui, Y.; Zhao, J.; Wang, Y.; Qin, S.; Lu, Y. Characterization and engineering of a dual-function diacylglycerol acyltransferase in the oleaginous marine diatom Phaeodactylum tricornutum. Biotechnol. Biofuels 2018, 11, 32. [CrossRef] [PubMed]

135. Wei, H.; Shi, Y.; Ma, X.; Pan, Y.; Hu, H.; Li, Y.; Luo, M.; Gerken, H.; Liu, J. A type-I diacylglycerol acyltransferase modulates triacylglycerol biosynthesis and fatty acid composition in the oleaginous microalga, Nannochloropsis oceanica. Biotechnol. Biofuels 2017, 10, 174. [CrossRef] [PubMed]

136. Li, D.-W.; Cen, S.-Y.; Liu, Y.-H.; Balamurugan, S.; Zheng, X.-Y.; Alimujiang, A.; Yang, W.-D.; Liu, J.-S.; Li, H.-Y. A type 2 diacylglycerol acyltransferase accelerates the triacylglycerol biosynthesis in heterokont oleaginous microalga Nannochloropsis oceanica. J. Biotechnol. 2016, 229, 65-71. [CrossRef] 
137. Yan, J.; Cheng, R.; Lin, X.; You, S.; Li, K.; Rong, H.; Ma, Y. Overexpression of acetyl-CoA synthetase increased the biomass and fatty acid proportion in microalga Schizochytrium. Appl. Microbiol. Biotechnol. 2013, 97, 1933-1939. [CrossRef]

138. Ma, Y.-H.; Wang, X.; Niu, Y.-F.; Yang, Z.-K.; Zhang, M.-H.; Wang, Z.-M.; Yang, W.-D.; Liu, J.-S.; Li, H.-Y. Antisense knockdown of pyruvate dehydrogenase kinase promotes the neutral lipid accumulation in the diatom Phaeodactylum tricornutum. Microb. Cell Fact. 2014, 13, 100. [CrossRef]

139. Xue, J.; Niu, Y.-F.; Huang, T.; Yang, W.-D.; Liu, J.-S.; Li, H.-Y. Genetic improvement of the microalga Phaeodactylum tricornutum for boosting neutral lipid accumulation. Metab. Eng. 2015, 27, 1-9. [CrossRef]

140. Xue, J.; Balamurugan, S.; Li, D.-W.; Liu, Y.-H.; Zeng, H.; Wang, L.; Yang, W.-D.; Liu, J.-S.; Li, H.-Y. Glucose-6-phosphate dehydrogenase as a target for highly efficient fatty acid biosynthesis in microalgae by enhancing NADPH supply. Metab. Eng. 2017, 41, 212-221. [CrossRef]

141. Sun, X.-M.; Ren, L.-J.; Zhao, Q.-Y.; Ji, X.-J.; Huang, H. Enhancement of lipid accumulation in microalgae by metabolic engineering. Biochim. Biophys. Acta-Mol. Cell Biol. Lipids 2019, 1864, 552-566. [CrossRef]

142. Tian, Q.-L.; Shi, D.-J.; Jia, X.-H.; Mi, H.-L.; Huang, X.-W.; He, P.-M. Recombinant expression and functional analysis of a Chlamydomonas reinhardtii bacterial-type phosphoenolpyruvate carboxylase gene fragment. Biotechnol. Lett. 2014, 36, 821-827. [CrossRef]

143. Wang, C.; Chen, X.; Li, H.; Wang, J.; Hu, Z. Artificial miRNA inhibition of phosphoenolpyruvate carboxylase increases fatty acid production in a green microalga Chlamydomonas reinhardtii. Biotechnol. Biofuels 2017, 10, 91. [CrossRef] [PubMed]

144. Yang, J.; Pan, Y.; Bowler, C.; Zhang, L.; Hu, H. Knockdown of phosphoenolpyruvate carboxykinase increases carbon flux to lipid synthesis in Phaeodactylum tricornutum. Algal Res. 2016, 15, 50-58. [CrossRef]

145. Nobusawa, T.; Yamakawa-Ayukawa, K.; Saito, F.; Nomura, S.; Takami, A.; Ohta, H. A homolog of Arabidopsis SDP1 lipase in Nannochloropsis is involved in degradation of de novo-synthesized triacylglycerols in the endoplasmic reticulum. Biochim. Biophys. Acta-Mol. Cell Biol. Lipids 2019, 1864, 1185-1193. [CrossRef] [PubMed]

146. Ibáñez-Salazar, A.; Rosales-Mendoza, S.; Rocha-Uribe, A.; Ramírez-Alonso, J.I.; Lara-Hernández, I.; Hernández-Torres, A.; Paz-Maldonado, L.M.T.; Silva-Ramírez, A.S.; Bañuelos-Hernández, B.; Martínez-Salgado, J.L.; et al. Over-expression of Dof-type transcription factor increases lipid production in Chlamydomonas reinhardtii. J. Biotechnol. 2014, 184, 27-38. [CrossRef]

147. Salas-Montantes, C.J.; González-Ortega, O.; Ochoa-Alfaro, A.E.; Camarena-Rangel, R.; Paz-Maldonado, L.M.T.; Rosales-Mendoza, S.; Rocha-Uribe, A.; Soria-Guerra, R.E. Lipid accumulation during nitrogen and sulfur starvation in Chlamydomonas reinhardtii overexpressing a transcription factor. J. Appl. Phycol. 2018, 30, 1721-1733. [CrossRef]

148. Kwon, S.; Kang, N.K.; Koh, H.G.; Shin, S.-E.; Lee, B.; Jeong, B.; Chang, Y.K. Enhancement of biomass and lipid productivity by overexpression of a bZIP transcription factor in Nannochloropsis salina. Biotechnol. Bioeng. 2018, 115, 331-340. [CrossRef]

149. Kang, N.K.; Jeon, S.; Kwon, S.; Koh, H.G.; Shin, S.-E.; Lee, B.; Choi, G.-G.; Yang, J.-W.; Jeong, B.; Chang, Y.K. Effects of overexpression of a bHLH transcription factor on biomass and lipid production in Nannochloropsis salina. Biotechnol. Biofuels 2015, 8, 200. [CrossRef]

150. Kang, N.K.; Kim, E.K.; Kim, Y.U.; Lee, B.; Jeong, W.-J.; Jeong, B.-R.; Chang, Y.K. Increased lipid production by heterologous expression of AtWRI1 transcription factor in Nannochloropsis salina. Biotechnol. Biofuels 2017, 10, 231. [CrossRef]

151. Li, D.-W.; Balamurugan, S.; Yang, Y.-F.; Zheng, J.-W.; Huang, D.; Zou, L.-G.; Yang, W.-D.; Liu, J.-S.; Guan, Y.; Li, H.-Y. Transcriptional regulation of microalgae for concurrent lipid overproduction and secretion. Sci. Adv. 2019, 5, 3795. [CrossRef]

152. Ajjawi, I.; Verruto, J.; Aqui, M.; Soriaga, L.B.; Coppersmith, J.; Kwok, K.; Peach, L.; Orchard, E.; Kalb, R.; $\mathrm{Xu}, \mathrm{W}$; et al. Lipid production in Nannochloropsis gaditana is doubled by decreasing expression of a single transcriptional regulator. Nat. Publ. Gr. 2017, 35, 647-652. [CrossRef]

153. Sharma, A.K.; Mühlroth, A.; Jouhet, J.; Maréchal, E.; Alipanah, L.; Kissen, R.; Brembu, T.; Bones, A.M.; Winge, P. The Myb-like transcription factor Phosphorus Starvation Response (PtPSR) controls conditional P acquisition and remodeling in marine microalgae. New Phytol. 2019. [CrossRef]

154. Torres-Romero, I.; Kong, F.; Légeret, B.; Beisson, F.; Peltier, G.; Li-Beisson, Y. Chlamydomonas cell cycle mutant crcdc5 over-accumulates starch and oil. Biochimie 2019. [CrossRef] 
155. Liu, J.; Sun, Z.; Mao, X.; Gerken, H.; Wang, X.; Yang, W. Multiomics analysis reveals a distinct mechanism of oleaginousness in the emerging model alga Chromochloris zofingiensis. Plant J. 2019, 98, 1060-1077. [CrossRef] [PubMed]

156. Zhang, X.; Wen, F.; Xu, Z.; Sun, D.; Chew, W.; Liu, J. De novo transcriptomic analysis of the oleaginous alga Botryococcus braunii AC768 (Chlorophyta). J. Appl. Phycol. 2019, 31, 255-267. [CrossRef]

157. D'Adamo, S.; Schiano di Visconte, G.; Lowe, G.; Szaub-Newton, J.; Beacham, T.; Landels, A.; Allen, M.J.; Spicer, A.; Matthijs, M. Engineering the unicellular alga Phaeodactylum tricornutum for high-value plant triterpenoid production. Plant Biotechnol. J. 2019, 17, 75-87. [CrossRef] [PubMed]

158. Jin, E.; Polle, J.E.W.; Lee, H.K.; Sang, M.; Man Chang, A. Xanthophylls in microalgae: From Biosynthesis to biotechnological mass production and application. J. Microbiol. Biotechnol. 2003, 13, 165-174.

159. Jin, E.; Polle, J.E.W.; Melis, A. Involvement of zeaxanthin and of the Cbr protein in the repair of photosystem II from photoinhibition in the green alga Dunaliella salina. Biochim. Biophys. Acta-Bioenerg. 2001, 1506, 244-259. [CrossRef]

160. Baek, K.L.; Yu, J.; Jeong, J.; Sim, S.J.; Bae, S.; Jin, E.S. Photoautotrophic production of macular pigment in a Chlamydomonas reinhardtii strain generated by using DNA-free CRISPR-Cas9 RNP-mediated mutagenesis. Biotechnol. Bioeng. 2018, 115, 719-728. [CrossRef]

161. Steinbrenner, J.; Sandmann, G. Transformation of the Green Alga Haematococcus pluvialis with a Phytoene Desaturase for Accelerated Astaxanthin Biosynthesis. Appl. Environ. Microbiol. 2006, 72, 7477-7484. [CrossRef]

162. Kathiresan, S.; Chandrashekar, A.; Ravishankar, G.A.; Sarada, R. Regulation of astaxanthin and its intermediates through cloning and genetic transformation of $\beta$-carotene ketolase in Haematococcus pluvialis. J. Biotechnol. 2015, 196-197, 33-41. [CrossRef]

163. Galarza, J.I.; Gimpel, J.A.; Rojas, V.; Arredondo-vega, B.O. Over-accumulation of astaxanthin in Haematococcus pluvialis through chloroplast genetic engineering. Algal Res. 2018, 31, 291-297. [CrossRef]

164. Couso, I.; Cordero, B.F.; Vargas, M.Á.; Rodríguez, H. Efficient heterologous transformation of Chlamydomonas reinhardtii npq2 mutant with the zeaxanthin epoxidase gene isolated and characterized from Chlorella zofingiensis. Mar. Drugs 2012, 10, 1955-1976. [CrossRef] [PubMed]

165. Eilers, U.; Bikoulis, A.; Breitenbach, J.; Büchel, C.; Sandmann, G. Limitations in the biosynthesis of fucoxanthin as targets for genetic engineering in Phaeodactylum tricornutum. J. Appl. Phycol. 2016, 28, 123-129. [CrossRef]

166. Lohr, M.; Schwender, J.; Polle, J.E.W. Isoprenoid biosynthesis in eukaryotic phototrophs: A spotlight on algae. Plant Sci. 2012, 185-186, 9-22. [CrossRef] [PubMed]

167. Lauersen, K.J.; Baier, T.; Wichmann, J.; Wördenweber, R.; Mussgnug, J.H.; Hübner, W.; Huser, T.; Kruse, O. Efficient phototrophic production of a high-value sesquiterpenoid from the eukaryotic microalga Chlamydomonas reinhardtii. Metab. Eng. 2016, 38, 331-343. [CrossRef] [PubMed]

168. Wichmann, J.; Baier, T.; Wentnagel, E.; Lauersen, K.J.; Kruse, O. Tailored carbon partitioning for phototrophic production of (E)- $\alpha$-bisabolene from the green microalga Chlamydomonas reinhardtii. Metab. Eng. 2018, 45, 211-222. [CrossRef] [PubMed]

169. Lauersen, K.J.; Wichmann, J.; Baier, T.; Kampranis, S.C.; Pateraki, I.; Møller, B.L.; Kruse, O. Phototrophic production of heterologous diterpenoids and a hydroxy-functionalized derivative from Chlamydomonas reinhardtii. Metab. Eng. 2018, 49, 116-127. [CrossRef]

170. Lin, P.-C.; Pakrasi, H.B. Engineering cyanobacteria for production of terpenoids. Planta 2019, 249, $145-154$. [CrossRef]

171. Nozzi, N.; Oliver, J.; Atsumi, S. Cyanobacteria as a Platform for Biofuel Production. Front. Bioeng. Biotechnol. 2013, 1, 7. [CrossRef]

172. Gao, X.; Gao, F.; Liu, D.; Zhang, H.; Nie, X.; Yang, C. Engineering the methylerythritol phosphate pathway in cyanobacteria for photosynthetic isoprene production from CO2. Energy Environ. Sci. 2016, 9, 1400-1411. [CrossRef]

173. Davies, F.K.; Work, V.H.; Beliaev, A.S.; Posewitz, M.C. Engineering Limonene and Bisabolene Production in Wild Type and a Glycogen-Deficient Mutant of Synechococcus sp. PCC 7002. Front. Bioeng. Biotechnol. 2014, 2, 21. [CrossRef] [PubMed]

174. Wang, X.; Liu, W.; Xin, C.; Zheng, Y.; Cheng, Y.; Sun, S.; Li, R.; Zhu, X.-G.; Dai, S.Y.; Rentzepis, P.M.; et al. Enhanced limonene production in cyanobacteria reveals photosynthesis limitations. Proc. Natl. Acad. Sci. USA 2016, 113, 14225-14230. [CrossRef] [PubMed] 
175. Lin, P.-C.; Saha, R.; Zhang, F.; Pakrasi, H.B. Metabolic engineering of the pentose phosphate pathway for enhanced limonene production in the cyanobacterium Synechocystis sp. PCC 6803. Sci. Rep. 2017, 7, 17503. [CrossRef] [PubMed]

176. Lauersen, K.J. Eukaryotic microalgae as hosts for light-driven heterologous isoprenoid production. Planta 2018. [CrossRef]

177. Baier, T.; Wichmann, J.; Kruse, O.; Lauersen, K.J. Intron-containing algal transgenes mediate efficient recombinant gene expression in the green microalga Chlamydomonas reinhardtii. Nucleic Acids Res. 2018, 46, 6909-6919. [CrossRef]

(C) 2020 by the authors. Licensee MDPI, Basel, Switzerland. This article is an open access article distributed under the terms and conditions of the Creative Commons Attribution (CC BY) license (http://creativecommons.org/licenses/by/4.0/). 